\title{
Southern Hemisphere Tropical Cyclone Climatology
}

\author{
Yuriy Kuleshov \\ National Climate Centre, Australian Bureau of Meteorology, Melbourne \\ School of Mathematical and Geospatial Sciences \\ Royal Melbourne Institute of Technology (RMIT) University, Melbourne \\ Australia
}

\section{Introduction}

Each year, around 80 tropical cyclones (TCs) form around the world, with about one-third of them in the Southern Hemisphere (SH) (Gray, 1979). Tropical cyclones within the South Indian Ocean (SIO) and the South Pacific Ocean (SPO) are frequent and intense, and they dramatically affect maritime navigation and the lives of communities in coastal areas. Australia and the island nations are affected each year by TCs. In extreme cases they can have devastating consequences on life, property and the economic well-being of the communities directly affected and the country as a whole, as in the case of one of Australia's most notorious TCs, Tracy, which devastated Darwin, the capital of the Northern Territory, on 25 December 1974 (Australian Government, 1977).

A number of high-impact TC events in the SH have occurred in recent years. In December 2002, TC Zoe (maximum intensity of $240 \mathrm{~km} / \mathrm{h}$ ) totally devastated the island of Tikopea in the SPO. Cyclone Heta developed in the SPO and reached a peak intensity of $235 \mathrm{~km} / \mathrm{h}$ on 5 January 2004. In Niue, the capital city of Alofi was devastated by the TC and two people left dead. In American Samoa, Heta destroyed over 600 homes and damaged 4,000 others; 20 people were injured. In March 2004, TC Gafilo affected northeastern Madagascar as the strongest cyclone to ever strike the country. Cyclone Gafilo made land-fall at peak intensity of $230 \mathrm{~km} / \mathrm{h}$, caused 283 fatalities and over US\$250M damage.

It is critical then that we have a full understanding of these disaster-inducing events. There is increasing evidence that the climate is changing on a global scale (IPCC, 2007) and consequently it is important to monitor changes in regional TC frequencies, intensities and tracks (Kuleshov and de Hoedt, 2003; Landsea, 2000a; Trenberth, 2007). Records show that TC frequency and spatial distribution have considerable inter-annual variability, and attempts have been made to find explanations for such variability. The role of El NiñoSouthern Oscillation (ENSO) in TC activity has been studied extensively. A significant reduction (increase) of TC activity over the Atlantic basin is observed during El Niño ( $\mathrm{La}$ Niña) events (Gray, 1984; Shapiro, 1987). There are significant spatial and temporal variations in TC activity over the western North Pacific associated with El Niño and La Niña events (Chan, 2000). El Niño events cause South Pacific TCs to occur further eastward than 
normal and also to bring about a general suppression of TC activity in the Coral Sea and north Australia region (Basher and Zheng, 1995; Gray, 1988).

Consequently, attempts have been made to utilise ENSO indices as predictors of TC activity (Chan, Shi and Liu, 2001; Landsea, 2000b; Saunders et al., 2000). However, criteria which different authors chose for defining ENSO phases vary. The lack of a common approach to defining ENSO phases makes it difficult to compare the outcomes of different studies. Recently, a number of key indices and derived lists of ENSO events identified by several studies have been examined by Kuleshov et al. (2009b) and a collective list of historical El Niño and La Niña events has been developed which may be recommended for subsequent studies on TC activity in the SH. In this chapter, variability and change in tropical cyclone occurrences across the $\mathrm{SH}$ is consistently analysed based on this developed approach.

\section{Tropical cyclone archive for the Southern Hemisphere}

The World Meteorological Organization (WMO) Tropical Cyclone Programme has established areas of responsibility for TC warning which extend across the regional bodies and also extend across the ocean basins (WMO, 2002a; WMO, 2002b). In the SH, the Regional Specialised Meteorological Centre (RSMC) in La Réunion is responsible for providing cyclone watch over the western SIO. The responsibility for the preparation of marine TC forecasts and warnings in the SPO and the eastern SIO is shared amongst Australia (Brisbane, Darwin and Perth Tropical Cyclone Warning Centres), Fiji (Nadi RSMC), Papua New Guinea (Port Moresby) and New Zealand (Wellington).

The National Meteorological and Hydrological Services (NMHSs) also archive records of TC occurrences in their areas of responsibility. Historical records of TC occurrences in the SH go back a few hundred years. For example, Australian records go back to the late 18th century. However, length of records in TC archives and their quality vary. It is widely accepted that TC records in the Australian region and the $\mathrm{SH}$ are complete and reliable after meteorological satellite came in operational use in the late 1960s (Holland, 1981).

Since 1999, considerable efforts were put in preparing consolidated historical TC records under an international initiative "Climate change and Southern Hemisphere tropical cyclones". As the first step, TC archive for the SH (jointly, SHTC) has been prepared at the National Climate Centre, Australian Bureau of Meteorology (ABM) (Kuleshov and de Hoedt, 2003). The archive is a result of multinational efforts of the NMHSs from the SH and has been derived from several different sources. The data for the western $\mathrm{SIO}\left(30^{\circ} \mathrm{E}\right.$ to $\left.90^{\circ} \mathrm{E}\right)$ have been provided by Météo-France (La Réunion), for the Australian region $\left(90^{\circ} \mathrm{E}\right.$ to $\left.160^{\circ} \mathrm{E}\right)$ by the $\mathrm{ABM}$, and for the eastern SPO (east of $160^{\circ} \mathrm{E}$ ) by the NMHSs of Fiji and New Zealand. TC tracks from these archives were merged in one archive, ensuring consistency of trajectories when TCs cross regional borders. Since then, data for the recent TC seasons have been regularly added to the SHTC archive and it now consists of TC best track data for the "satellite era" i.e. the TC seasons from 1969/70 to 2009/10, covering name (and/or unique identification number), position and intensity (in terms of central pressure) (Kuleshov et al., 2010a).

The availability of satellite imagery has significantly improved our knowledge of TCs, with satellite remote sensing being vital for accurate estimates of parameters such as TC intensity and position (e.g. the location of minimum atmospheric pressure). Satellite images are used by forecasters for preparing operational and best track data, and a complete digital 
Geostationary Meteorological Satellite (GMS) archive for the SH was prepared by the ABM for use in TC reanalysis (Broomhall et al. 2010).

Currently, the technique for estimating TC intensity is the Dvorak analogue procedure based on patterns of infra-red brightness temperature (Dvorak, 1984, Velden et al., 2006). The original version of the technique, applied to visible satellite imagery, was published in 1975 , with its present form, based on digital infra-red imagery, published in 1984. While polar-orbiting satellite images became available in the Australian region from late 1960s (Holland 1984), geostationary satellite imagery became available only in 1978 and it was only during the mid-1980s that high-resolution multi-channel imagery became available at the Australian Region forecast offices. For the western SIO where the tracks are maintained by Météo-France (La Réunion), significant improvement in data quality and estimation of cyclone intensity occurred with the beginning of geostationary satellite coverage in 1998, as a result of the launch of the MeteoSat-7 satellite (Kossin et al. 2007). Within the satellite era, low-resolution geostationary satellite imagery for the SPO (west of about $155^{\circ} \mathrm{W}$ ) became available to forecasters from Fiji and New Zealand from 1980. However, only from the early 1990s, with high-resolution imagery from the GOES-West satellites available, did the Dvorak technique become increasingly used for estimating storm intensity.

This variation between different regions, in the time period for which high resolution satellite imagery is available, influences the accuracy of cyclone intensity estimations and imposes limitations on the analysis of historical data. For example, it restricts the accuracy of long-term trend analysis of changes in cyclone intensity - something required to address the important question of how TC activity is changing over decades and possible relationships to global climate change. Consequently, reanalysis of the historical TCs in order to obtain globally homogeneous records is essential (Kuleshov et al. 2010b).

Numerous studies have analysed TC occurrence in the SH (e.g. Kerr, 1976; Revell, 1981; Revel and Goulter, 1986). Nicholls (1985) attributed an increasing trend observed in the number of TCs in the SH, with fewer TCs observed at the beginning of the century, to the improvements in observing systems and networks during this time period. However, strong interannual variability in TC activity occurs around this trend, and Nicholls (1992) showed evidence of a strong statistical link between these inter-seasonal fluctuations of TC numbers and the ENSO phenomenon.

\section{Influence of EI Niño-Southern Oscillation on tropical cyclone activity}

The ENSO is the most important coupled ocean-atmosphere phenomenon affecting interannual climate variability on a global scale. ENSO consists of three phases: El Niño (the warm phase), La Niña (the cold phase) and the neutral phase. Despite the fact that ENSO has been the subject of numerous studies over recent decades, there is as yet no international agreement on a definition of ENSO and its phases. Usually, ENSO definitions are based on a quantitative analysis of (i) the intensity of the Southern Oscillation (SO) using indices linked with atmospheric pressure gradients and/or (ii) sea surface temperature (SST) anomalies in the Pacific (equatorial or near-equatorial regions). It is common practice to describe the strength of the SO in terms of a Southern Oscillation Index (SOI), for example the Troup Index (Troup 1965), or mean sea level pressure at certain stations such as Darwin (Australia), Papeete (Tahiti), etc. Area-averaged SST anomalies (SSTAs) in various regions such as the NINO3, NINO3.4 and NINO4 regions are commonly used indices to describe 
oceanic conditions in the Pacific region. However, ENSO is a coupled ocean-atmosphere phenomenon, and combining both atmospheric and oceanic responses in a composite index seems to be a more appropriate index-based approach to a comprehensive description of the phenomenon than using atmospheric and oceanic indices alone. Lack of consensus on a definition of El Niño ( $L a$ Niña) events typically results in certain warm (cold) episodes being included or excluded from lists of ENSO events compiled by different scientists.

It has been shown that ENSO is a significant contributor to the year-to-year variability in TC activity in most ocean basins (Nicholls 1984, Chan 2000, Landsea 2000b, Saunders et al. 2000, Kuleshov et al., 2008). Once again, the above-mentioned absence of agreement on defining ENSO warm and cold phases leads to investigators employing different criteria in the delineation of El Niño and La Niña events. Thus, NINO3.4 $\left(5^{\circ} \mathrm{N}-5^{\circ} \mathrm{S}, 120^{\circ}-170^{\circ} \mathrm{W}\right)$ SSTA thresholds of above $+0.3^{\circ} \mathrm{C}\left(\right.$ below $\left.-0.3^{\circ} \mathrm{C}\right)$ for identifying El Niño (La Niña) were used by Saunders et al. (2000) to investigate ENSO spatial impacts on occurrence and landfall of TCs in the Atlantic and Northwest Pacific basins. On the other hand, while studying TC activity over the Northwest Pacific, Chan (2000) referred to El Niño (La Niña) years if SSTAs in the NINO3.4 region rose above $+0.5^{\circ} \mathrm{C}\left(\right.$ fell below $\left.-0.5^{\circ} \mathrm{C}\right)$ sometime during that year. Consequently, even though significant ENSO impact on TC activity has been demonstrated, quantitative comparison of the results from different studies is somewhat difficult.

In this section, some key ENSO indices are examined in an attempt to develop a collective list of historical El Niño and La Niña events which may be recommended for subsequent studies on TC activity in the SH. The NINO3.4 SSTA and the SOI are the two most commonly used indices in defining ENSO phases. The SOI data used in this analysis were obtained from the ABM (www.bom.gov.au/climate/current/) and values for the NINO3.4 SSTA (3-month running mean) - from the Climate Prediction Center, NOAA (ftp.cpc.ncep.noaa.gov/wd52dg/data/indices/).

The Multivariate ENSO Index (MEI) (Wolter 1987) was also used to quantify the start and end of ENSO events (www.cdc.noaa.gov/people/klaus.wolter/MEI/table.html). Another multivariate ENSO index, based on the first principal component of monthly Darwin mean sea level pressure (MSLP), Tahiti MSLP, and the NINO3, NINO3.4 and NINO4 SST indices, was developed and examined. Its base period is 1950-1999. We will denote this (standardised monthly) index the 5VAR index (Kuleshov et al., 2009b). It has a distinct advantage over the MEI in that it can be consistently extended further back in time.

Based on findings from early studies (Trenberth 1997, Reid 2003), the following assumptions have been made to evaluate the indices: the Pacific exhibits El Niño conditions approximately $31 \%$ of the time, La Niña conditions $23 \%$, and neutral conditions $46 \%$. Bimonthly MEI values (in multiples of the standard deviation) for the period from Dec 1949/Jan 1950 to Dec 2005/Jan 2006 were ranked from lowest to highest. Applying the above assumptions to the period 1950 to 2005 (56 years), a warm (cold) ENSO episode was identified if the MEI ranks for at least five consecutive months were greater than or equal to $39 \approx(1-0.31) \times 56$ (less than or equal to $13 \approx 0.23 \times 56$ ). Another list of ENSO episodes was derived in an analogous fashion using the 5VAR index. The El Niño and La Niña events in these two lists, as identified by the MEI and 5VAR index ranks, were compared with the lists of ENSO events from Rasmusson and Carpenter (1982), Kiladis and van Loon (1988), Trenberth (1997), Larkin and Harrison (2001, 2002) and Reid (2003). 
For the $\mathrm{SH}$, the TC year was considered as the 12 month period from July to June inclusive. In general, the main historically-recognized ENSO events included in the lists of examined publications were identified by the MEI rank and the 5VAR index rank using the selected thresholds. As a result, the following TC years are considered as El Niño seasons: 1951/52, 1957/58, 1963/64, 1965/66, 1969/70, 1972/73, 1976/77, 1977/78, $1979 / 80,1982 / 83,1986 / 87,1987 / 88,1991 / 92,1992 / 93,1993 / 94,1994 / 95,1997 / 98$, 2002/03, 2004/05, 2006/07 and 2009/10. The corresponding list of La Niña seasons is $1950 / 51,1954 / 55,1955 / 56,1956 / 57,1961 / 62,1964 / 65,1970 / 71,1973 / 74,1974 / 75$, 1975/76, 1988/89, 1998/99, 1999/2000, 2007/2008 and 2010/11. The developed list of historical El Niño and La Niña events has been used for analysis of TC variability and change across the $\mathrm{SH}$ presented in the following sections.

\section{Variability and change in tropical cyclone occurrences across the Southern Hemisphere}

Analysis of data from the SHTC archive has confirmed that ENSO is a significant contributor to the year-to-year variability in TC activity in the SPO and SIO. This clearly raises important questions about the future direction of TC change under the enhanced greenhouse effect. For example, a more El Niño-like future may lead to substantially increased frequencies of TCs in some regions and reduced frequencies in others.

The number of times a TC crosses a particular longitude has been found to provide a useful statistics in TC track studies (Hall and Jewson, 2007; WMO 1993). The convention adopted here takes into account multiple crossings of the same longitude by the same TC. Average annual profiles of TC longitude crossings for El Niño and La Niña years are presented in Figure 1. Comparing the profiles, geographical shifts in TC occurrences and changes in intensity of the maxima are evident. In the Australian region, a higher TC impact on the coastal area (between $110^{\circ} \mathrm{E}$ and $155^{\circ} \mathrm{E}$ ) in La Niña years than in El Niño years was observed. TC impacts on island nations in the SIO and SPO also vary. During El Niño years, TCs tend to occur further eastwards in the SPO. In the western SIO, the position of maximum TC activity shifts eastwards in La Niña years compared to El Niño years.

Spatial profiles for the three phases of ENSO (El Niño, La Niña and neutral) have been constructed, and expressed as departures from climatology (Figures 2A, 2B and 2C, respectively). The graph of anomalous average annual TC longitude crossings for El Niño years shows a general decrease in TC activity in the areas west of $60^{\circ} \mathrm{E}$ and between $80^{\circ} \mathrm{E}$ and $165^{\circ} \mathrm{W}$, and an increase of TC activity in the SPO east of $165^{\circ} \mathrm{W}$ and in the SIO between $60^{\circ} \mathrm{E}$ and $80^{\circ} \mathrm{E}$ (Figure 2A). The departure from climatology for La Niña years indicates an almost directly opposite effect on TC activity: it is above climatology in the areas west of $55^{\circ} \mathrm{E}$ and between $70^{\circ} \mathrm{E}$ and $180^{\circ}$, and below climatology in the SPO east of $180^{\circ}$ and in the SIO between $55^{\circ} \mathrm{E}$ and $70^{\circ} \mathrm{E}$ (Figure $2 \mathrm{~B}$ ). The graph for departure from climatology of TC longitude crossings for neutral years demonstrates that TC activity generally stays close to the climatology (Figure 2C). The mean number of average annual TC longitude crossings in the $\mathrm{SH}$ is 2.8 (climatology) decreasing to 2.7 in neutral years, which represents a less than $4 \%$ reduction in the mean. From this analysis it is evident that ENSO has a significant influence on changes in areas favourable for TC genesis and consequently on geographical variation in TC tracks in the $\mathrm{SH}$. 


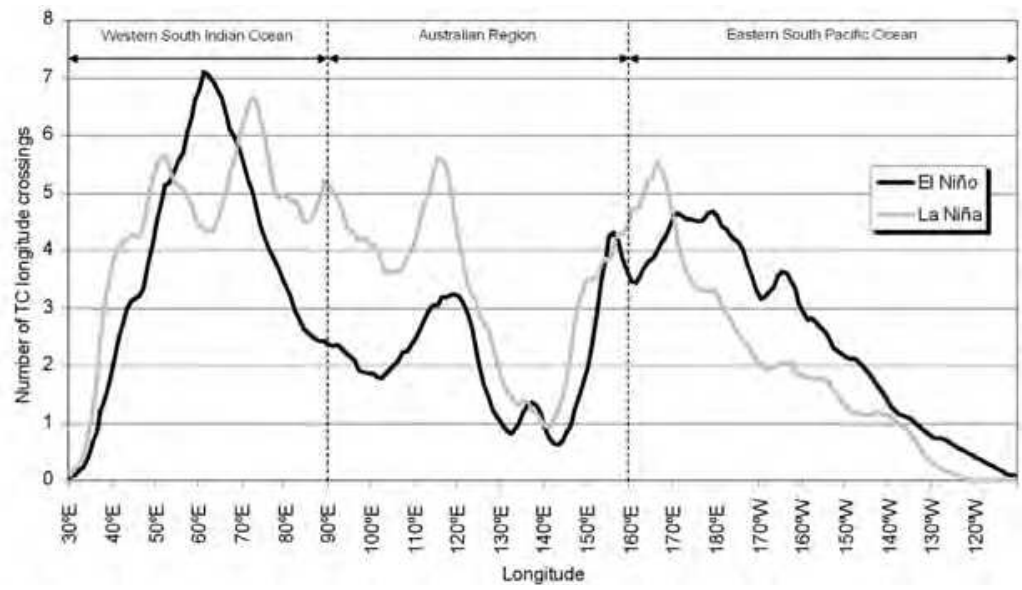

Fig. 1. Average annual profiles (5-point smoothed) for TC longitude crossings for El Niño and La Niña years.

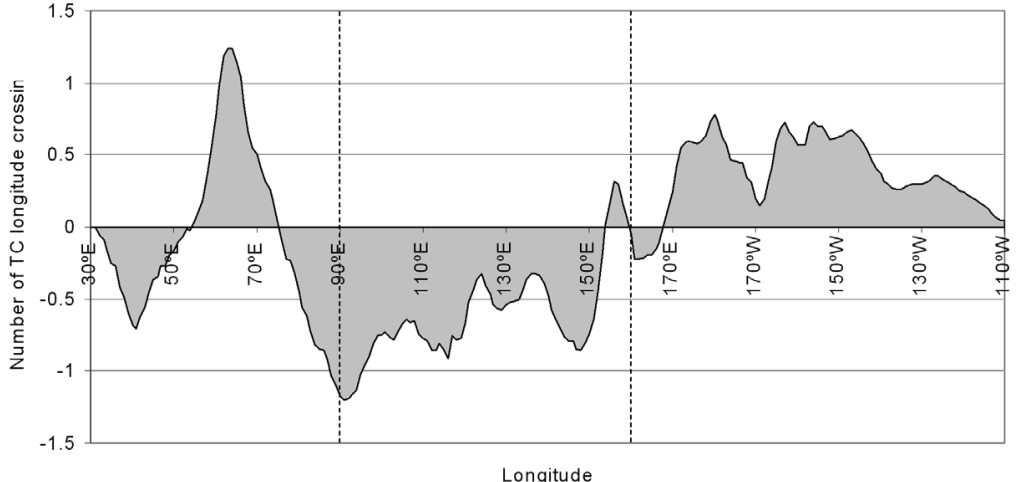

(a)

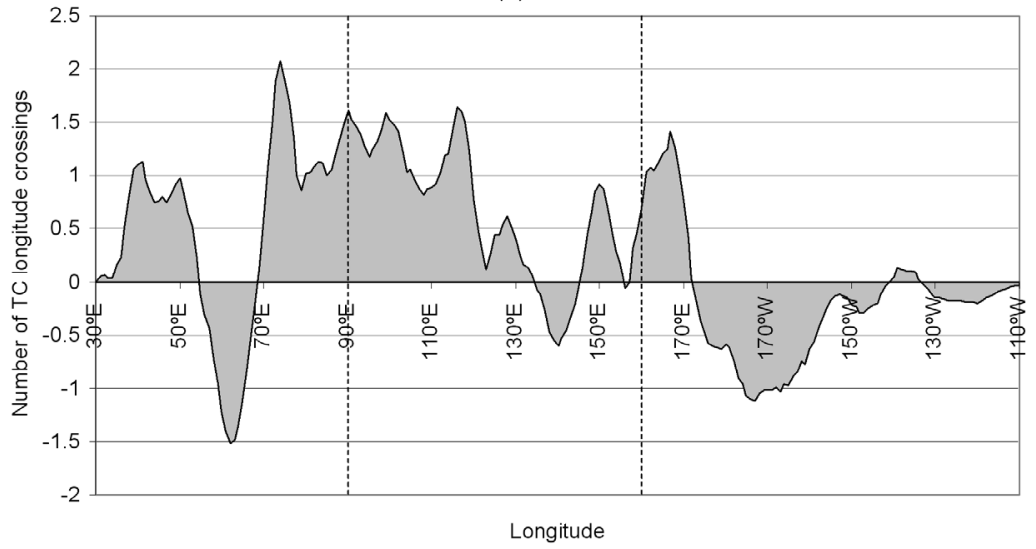

(b) 


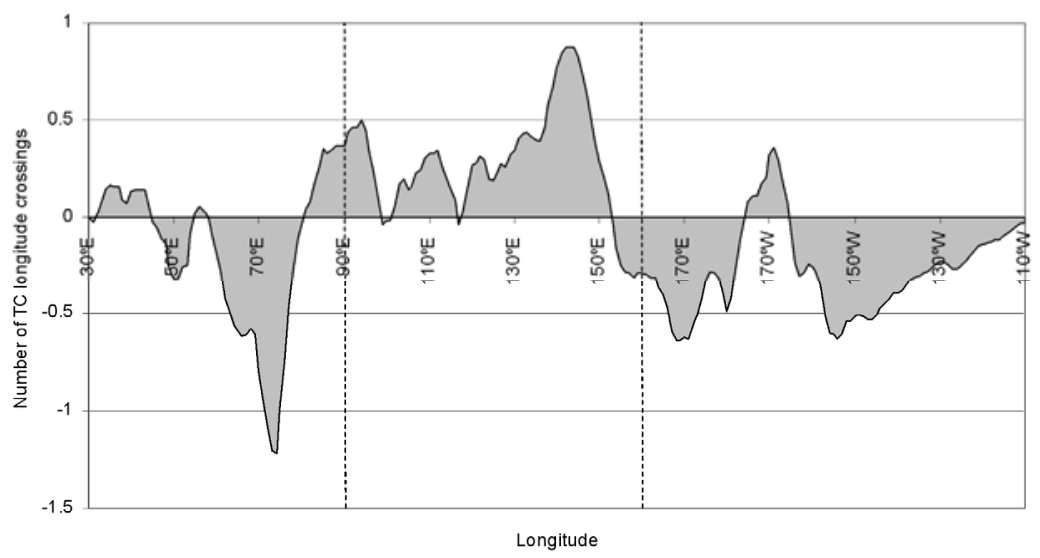

(c)

Fig. 2. Departure from climatology of average annual TC longitude crossings (5-point smoothed) for (A) El Niño, (B) La Niña and (C) neutral years. Vertical dashed lines indicate regional boundaries for the western South Indian Ocean, the Australian region and the eastern South Pacific Ocean as per Figure 1.

\section{Large-scale environmental variables which influence tropical cyclone genesis and development}

Influence of the ENSO phenomenon on TC activity in the various regions of the $\mathrm{SH}$ has been demonstrated in numerous studies (Nicholls, 1984; Hastings, 1990; Evans and Allen, 1992; Basher and Zheng, 1995; Nicholls et al., 1998; Camargo et al., 2007; Kuleshov et al., 2008). It is well known that the ENSO also plays an important role in TC interannual variability in ocean basins of the Northern Hemisphere (e.g. Chu, 2004), although the influence of large-scale environmental factors on TC genesis and development varies for different basins. Gray (1979) formulated six large-scale environmental parameters playing key roles in formation of TCs including the Coriolis parameter, low-level relative vorticity, relative humidity in the mid-troposphere, tropospheric vertical wind shear, ocean thermal energy, and difference in equivalent potential temperature between the surface and $500 \mathrm{hPa}$. Recently, Camargo et al. (2007) used a genesis potential index which is similar to Gray's seasonal genesis index (Gray, 1979) to diagnose ENSO effects on tropical cyclogenesis and concluded that in the basins of the $\mathrm{SH}$ vertical wind shear and mid-tropospheric relative humidity are especially important, vorticity anomalies contribute most significantly in the central Pacific, and thermodynamic variable of the genesis potential index described in terms of potential intensity (Bister and Emanuel, 1998) plays a secondary role. It is well established that vertical wind shear in the Northern Hemisphere, particularly in the North Atlantic, plays a primary role in TC variability related to the ENSO (e.g. Gray 1984). However, in the SH it is less obvious because of strong gradients in wind-shear over the regions of cyclogenesis. Also, changes in SSTs related to changes in ENSO phases are significant in the equatorial and near-equatorial regions of the Indian and Pacific Oceans, and it appears that the thermodynamic variable 
can be in addition one of the important environmental factors contributing to tropical cyclogenesis variability in this region. Thus, it is pertinent to further examine influence of changes in TC surrounding environment on TC genesis. Based on results of earlier studies, large scale environmental factors which influence TC genesis and development such as SST, relative humidity, vertical wind shear and relative vorticity were examined here through the National Center for Environmental Prediction (NCEP) composite reanalysis dataset (Kalnay et al., 1996).

The SIO is the least studied basin in terms of analysis of relationship between cyclones and their environment (Kuleshov et al. 2010b). Only a few studies attempted to investigate critical environmental factors which govern SIO cyclone activity. An attempt to establish relationship between ENSO and SIO cyclone numbers was made by Jury (1993); however, no statistically significant correlation was found between the number of cyclones that occur and an index of ENSO activity (the SOI). Examining variation in geographical distribution of cyclone variability, Ho et al. (2006) and Kuleshov et al. (2008) demonstrated that the tropical cyclogenesis area tends to shift west in El Niño when compared with La Niña years. A number of environmental factors critical for SIO cyclone development has been identified. For example, Kuleshov et al. (2009a) attribute shifts in cyclone tracks during ENSO phases to changes in vorticity and relative humidity and Camargo et al. (2007) showed that the track shifts are primarily due to changes in vertical wind shear.

Analysing geographical variation in TC activity in the SPO, Basher and Zheng (1995) and Kuleshov et al. (2009a) have demonstrated that cyclones tend to form in the southwest of the basin in La Niña years compared with El Niño years. A plausible explanation for this eastwest shift is change in distribution of the sea surface temperatures over the Pacific during El Niño and La Niña. In El Niño years, positive anomalies of the sea surface temperatures occur in the central and eastern Pacific compared with La Niña years which explains the observed shift in tropical cyclogenesis (Kuleshov et al., 2009a). Camargo et al. (2007) and Kuleshov et al. (2009a) have demonstrated that relative humidity and vertical wind shear are important factors of the environment in which TCs form and develop in the SH. Kuleshov et al. (2009a) also found that anomalously enhanced pre-existing cyclonic vorticity tends to occur in the southwest part of the basin in La Niña years, and this anomaly tends to exist further northeast in El Niño years.

In the following sub-sections, detailed analysis of TC activity and its relationship to ENSO is presented. For the $\mathrm{SH}$, the TC year is considered as the 12 month period from July to June inclusive. Fields of the SST, relative humidity in mid-troposphere, vertical wind shear and lower tropospheric vorticity have been obtained from the NCEP re-analysis dataset (Kalnay et al., 1996). Geographical boundaries for the SIO basin are defined as south to the equator, west of $135^{\circ} \mathrm{E}$, and for the $\mathrm{SPO}$ basin as south to the equator, east of $135^{\circ} \mathrm{E}$.

\subsection{Tropical cyclone genesis}

Spatial distribution of TC genesis over the SIO basin during all TC seasons from 1969 to 2006, including El Niño, La Niña and neutral phases of ENSO is presented in Fig. 3. In this analysis, a cyclogenesis point is defined by locating a point along cyclone track where an estimated TC central pressure attained a threshold of $1000 \mathrm{hPa}$ or lower. In the SIO, TC genesis is observed over the whole range of longitudes of the basin. The maximum occurrence is located in the 
area around $\left[5-15^{\circ} \mathrm{S}, 60-130^{\circ} \mathrm{E}\right]$. In the area between African coast and $60^{\circ} \mathrm{E}$, there is a noticeable displacement of the points of TC genesis southwards to $10-25^{\circ} \mathrm{S}$.

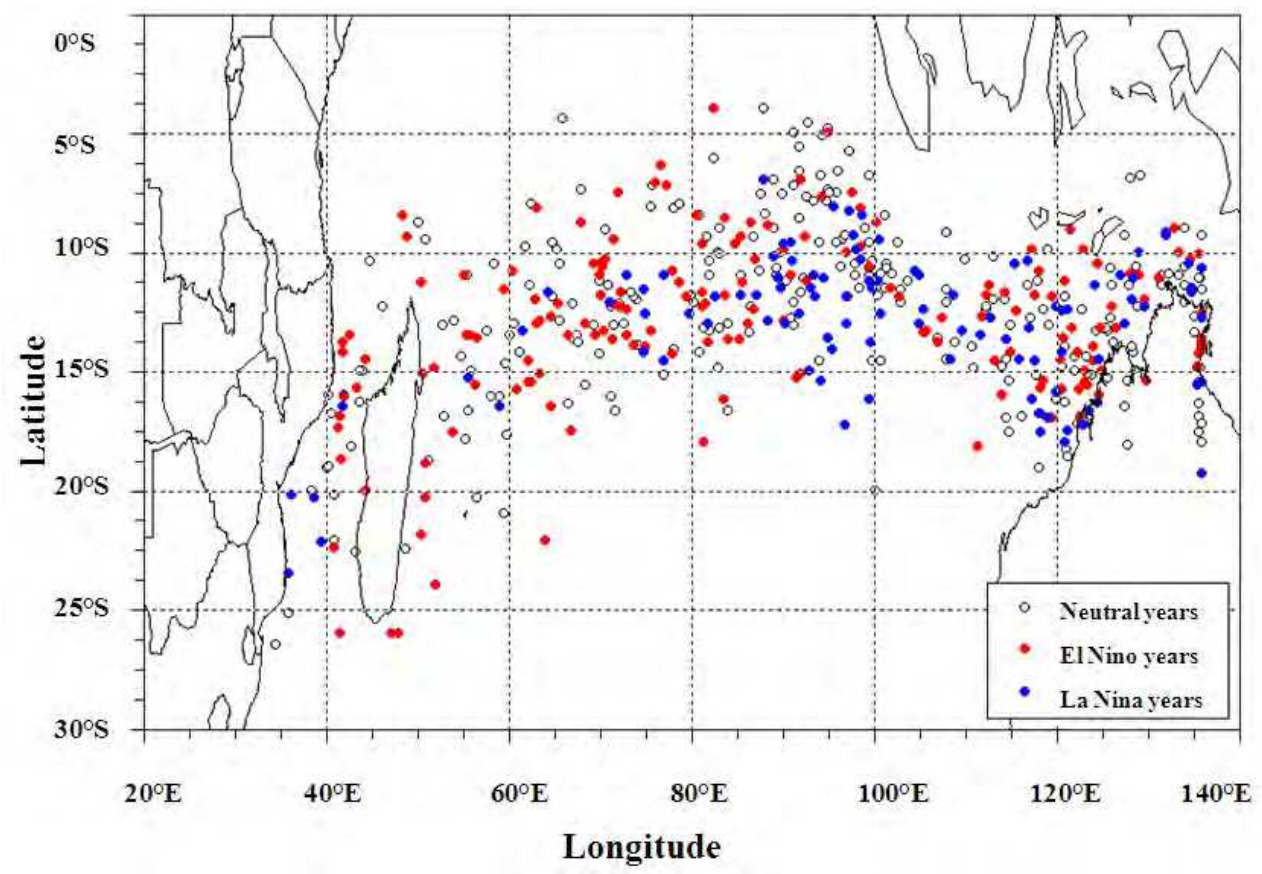

Fig. 3. Geographical distribution of tropical cyclogenesis events over the South Indian Ocean for the period 1969-2006.

Analysis of composite cyclogenesis anomalies demonstrates that during El Niño episodes (Fig. 4a) TC genesis is above climatology in the western part of the basin (west of around $85^{\circ} \mathrm{E}$ ) with the maximum located around $\left[15^{\circ} \mathrm{S}, 65^{\circ} \mathrm{E}\right]$ and it is below climatology in the eastern part of the basin (east of around $85^{\circ} \mathrm{E}$ ) with the minimum in the area centred around $\left[10^{\circ} \mathrm{S}, 9^{\circ} \mathrm{E}\right]$ (results in this area are significant at $90 \%$ level). To evaluate significance of the results, the Student t-test is employed in here, with the null hypothesis that the anomaly is not significantly different from zero. It should be noticed that the results from this significance test need to be treated cautiously because of the relatively small size of TC data sample. As mentioned in the section 2, the reliable TC records in the SH start with the beginning of the satellite era in late 1960s - early 1970s. As an effort to increase the sample size, a relatively large grid box, $6^{\circ}$ by $6^{\circ}$, is selected for the analysis in this analysis. [Similar approach was applied by Chan (2000) for studying TC activity over the western North Pacific associated with El Niño and La Niña events.] A large area with test values greater than the specified significance threshold is likely to be true for individual seasons.

During La Niña episodes (Fig. 4b), increase of TC genesis is observed in the eastern part of the basin (east of about $85^{\circ} \mathrm{E}$ ) with a primary cyclogenesis maximum in the area located off 
the northwest coast of Western Australia around $\left[15^{\circ} \mathrm{S}, 120^{\circ} \mathrm{E}\right]$ and a secondary $\mathrm{TC}$ genesis maximum centred around $\left[15^{\circ} \mathrm{S}, 95^{\circ} \mathrm{E}\right]$ (both passed the significance test at $90 \%$ level).

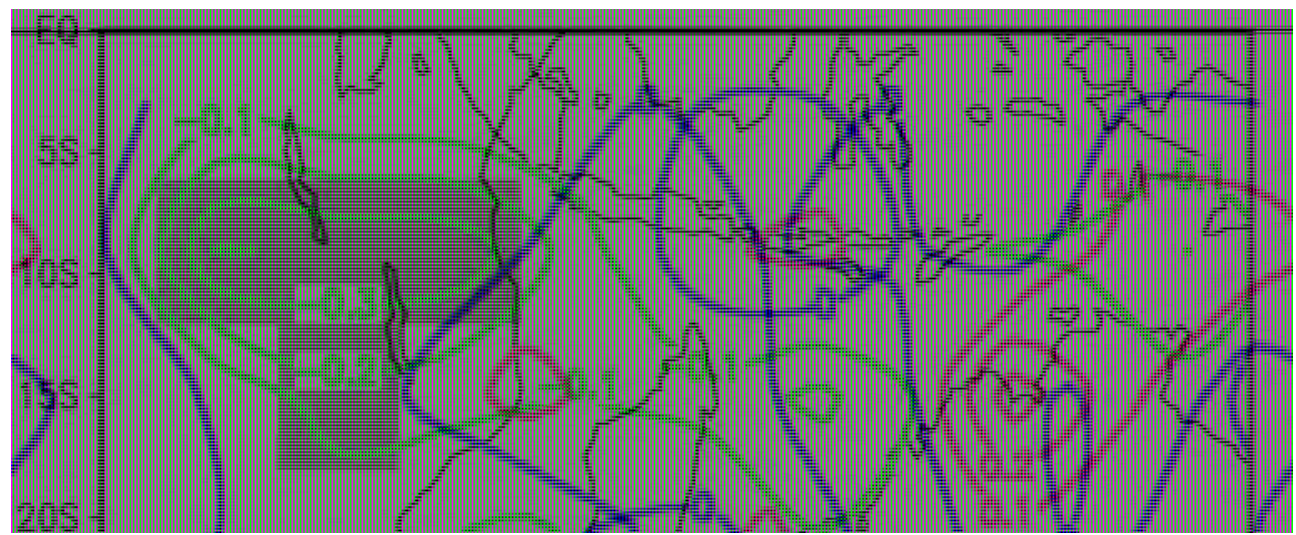

(a)

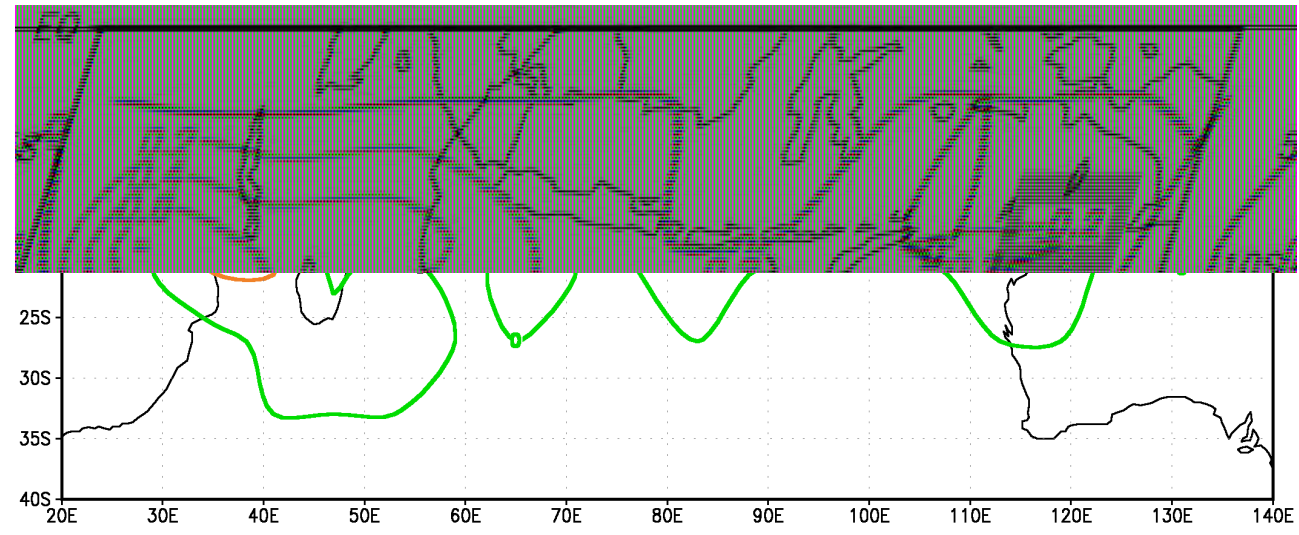

(b)

Fig. 4. Composite anomalies of the average annual number of tropical cyclogenesis in the South Indian Ocean during (a) El Niño and (b) La Niña in $6^{\circ} \times 6^{\circ}$ boxes. The shades indicate areas where the statistical test is significant at the $90 \%$ level.

Spatial distribution of TC genesis over the SPO basin during all TC seasons from 1969 to 2006 is shown in Fig. 5. Points of cyclogenesis are observed over the range of longitudes between $135^{\circ} \mathrm{E}$ and $120^{\circ} \mathrm{W}$. A comparison between cyclogenesis events during El Niño, La Niña and neutral seasons (Fig. 5) reveals that points of TC genesis are displaced towards southwest during La Niña seasons compared to El Niño seasons. This result is in agreement with previous studies on TCs in the Southwest Pacific Ocean (Gray, 1988; Basher and Zheng, 1995). 


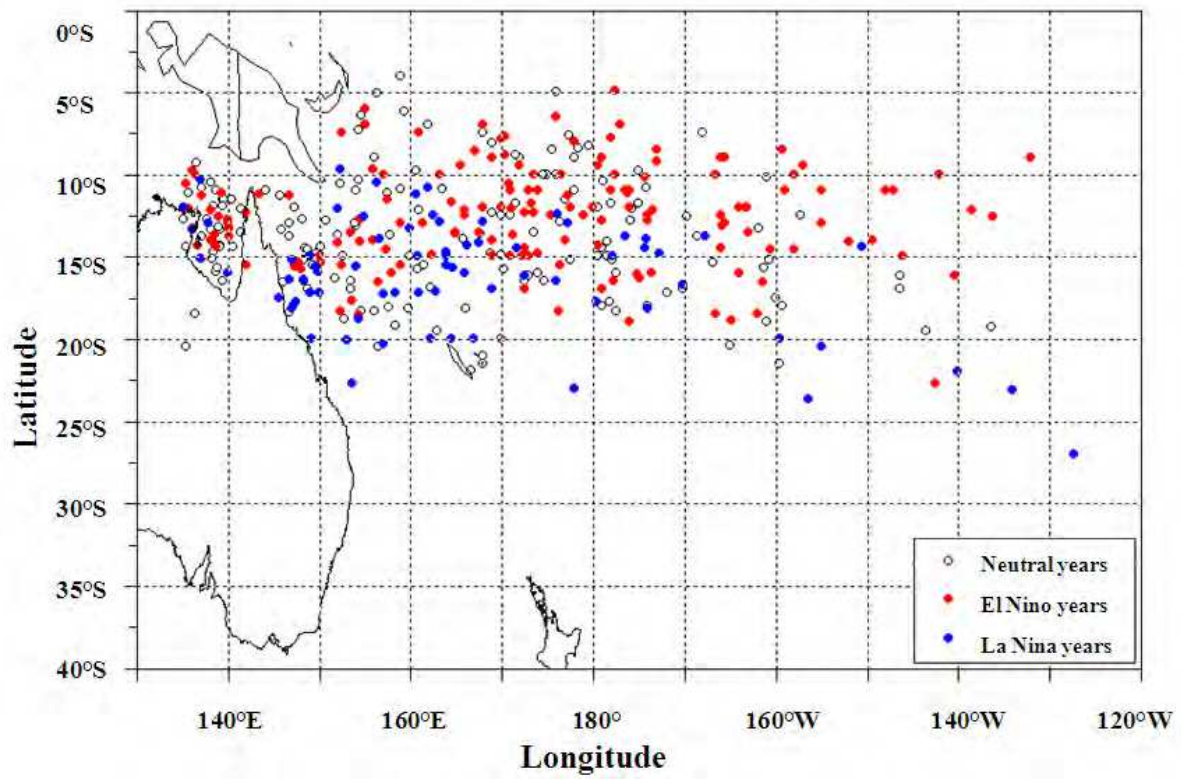

Fig. 5. Geographical distribution of tropical cyclogenesis events over the South Pacific Ocean for the period 1969-2006.

Analysis of spatial distribution of tropical cyclogenesis during the El Niño seasons (Fig. 6a) shows that a large area of above climatology TC genesis is located in the eastern part of the basin east of the line $\left[10^{\circ} \mathrm{S}, 165^{\circ} \mathrm{E}-20^{\circ} \mathrm{S}, 175^{\circ} \mathrm{E}\right]$. During La Niña seasons (Fig. 6b), area of active TC genesis is displaced southwest to around [10 $\left.-20^{\circ} \mathrm{S}, 145-170^{\circ} \mathrm{E}\right]$ (statistically significant at $90 \%$ level) and TC activity in the central near-equatorial area of the basin around $\left[5-15^{\circ} \mathrm{S}, 170^{\circ} \mathrm{E}-170^{\circ} \mathrm{W}\right]$ is below the climatology.

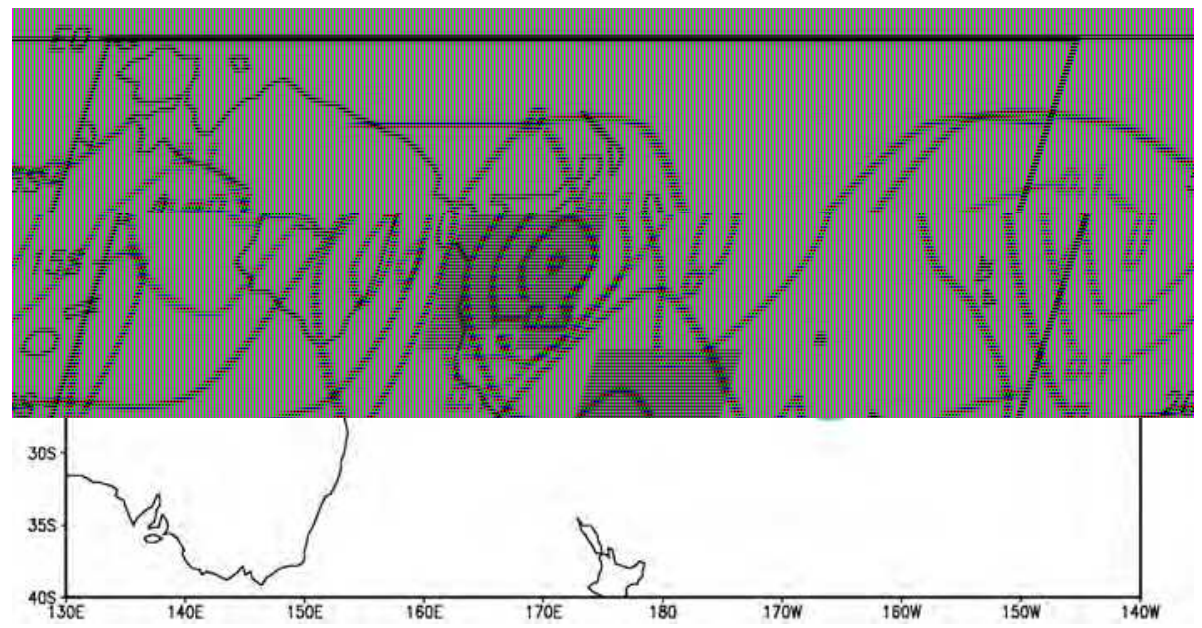

(a) 


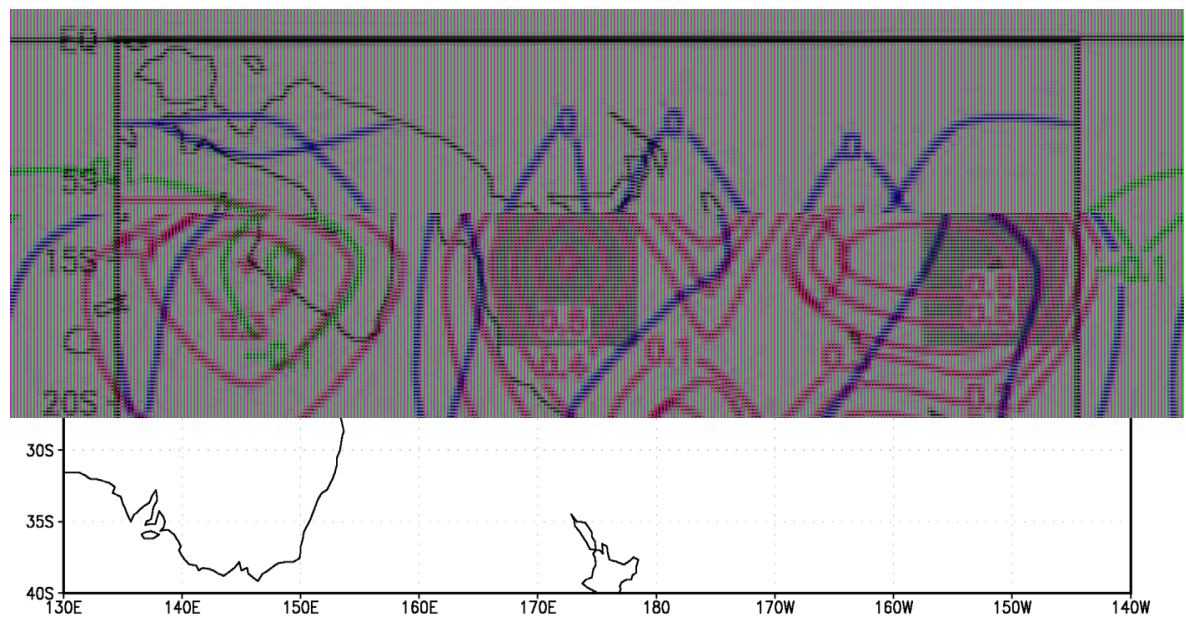

(b)

Fig. 6. Composite anomalies of the average annual number of tropical cyclogenesis in the South Pacific Ocean during (a) El Niño and (b) La Niña episodes in $6^{\circ} \times 6^{\circ}$ boxes. The shades indicate areas where the statistical test is significant at the $90 \%$ level.

\subsection{Sea surface temperature distribution}

Ocean thermal energy is an important contributor to TC genesis and according to Gray (1979) ocean temperatures greater than $26^{\circ} \mathrm{C}$ to a depth of 60 meters is an essential climatological aspect of the seasonal frequency of TC formation at any location. To evaluate temperature's geographical distribution over the two oceanic basins, the SST climatology was firstly derived based on 1968 to 1996 period as defined by Physical Sciences Division, National Oceanic and Atmospheric Administration (NOAA). In the SIO, during both warm and cold ENSO phases oceanic conditions in terms of SSTs above $26^{\circ} \mathrm{C}$ (Gray 1979) are favourable over the near-equatorial belt between the equator and about $15^{\circ} \mathrm{S} 25^{\circ} \mathrm{S}$ (Figure not shown). Thus, it appears that changes in geographical distribution of SSTs over the basin related to warm and cold phases of ENSO rather than temperature values per se influence changes in TC genesis.

Analysing average SST anomaly fields (SSTAs) from November to April, it was found that positive SSTAs are present nearly over the whole range of longitudes between the equator and about $30-35^{\circ} \mathrm{S}$ during El Niño events except for a relatively small area around $\left[35^{\circ} \mathrm{S}\right.$, $60^{\circ} \mathrm{E}$ ] (Fig. 7a; shaded areas indicate where statistical tests are significant at $95 \%$ level). Strong positive anomalies are observed in the central parts of the basin with maximum values greater than $0.4^{\circ} \mathrm{C}$, which can contribute to increased TC genesis in those areas in El Niño seasons. The area of enhanced cyclogenesis located around [15ㅇ, 65 $\left.{ }^{\circ} \mathrm{E}\right]$ (Fig. 4a) matches the significant positive SSTAs in the same region quite well.

During La Niña seasons, positive SSTAs observed over the basin in El Niño seasons (Fig. 7a) are replaced by negative SSTAs which are found over the most areas in the SIO from the equator to about $30^{\circ} \mathrm{S}$ except for the central and southern areas off Western Australia coastline (Fig. 7b). This contrast in the SST distribution over the basin during La Niña seasons can 
partially explain displacement of area favourable for cyclogenesis to the eastern part of the basin closer to the coast of Western Australia (Fig. 4) where the warmer SSTs are present.

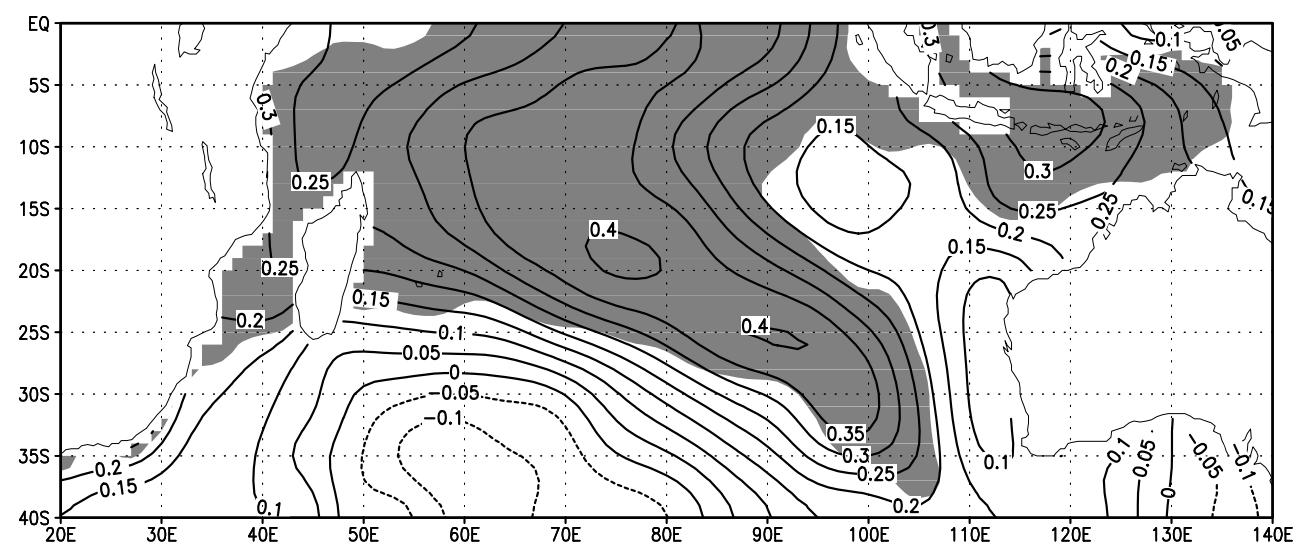

(a)

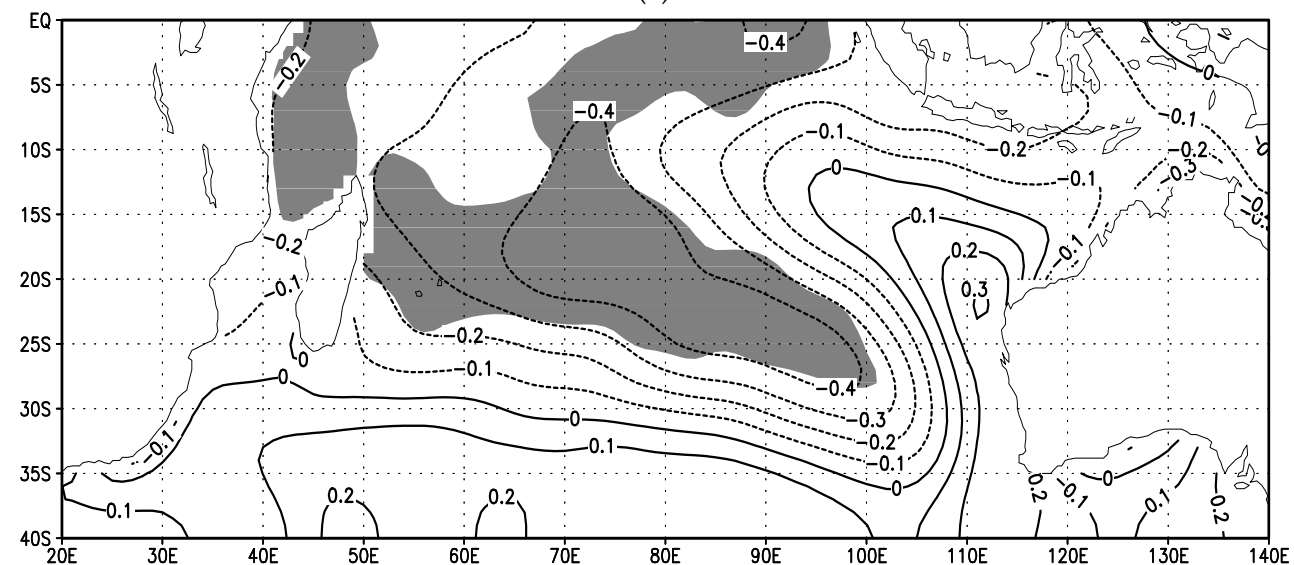

(b)

Fig. 7. SST anomalies $\left({ }^{\circ} \mathrm{C}\right)$ from November to April in the South Indian Ocean during (a) El Niño and (b) La Niña episodes. The shades indicate areas where the statistical test is significant at the $95 \%$ level.

During El Niño seasons, the SSTAs are positive in the near-equatorial area and in the eastern part of the SPO basin, with maximum positive anomalies in the area around $\left[0-15^{\circ} \mathrm{S}, 160^{\circ} \mathrm{E}-\right.$ $140^{\circ} \mathrm{W}$ ] (Fig. 8a), while across the Coral Sea, there is a narrow zone of negative anomalies extending southeastward to the central and eastern parts of the basin. The positive SSTAs promote TC genesis and development further eastwards in the basin in El Niño seasons when compared with La Niña seasons (Fig. 6). During La Niña seasons, negative SSTAs replacing a large area between the equator and $15^{\circ} \mathrm{S}$ (Fig. 8b) inhibit TC genesis and contribute to displacing area preferable for TC genesis southwest compared to El Niño seasons (Fig. 6b). Warmer than climatological average waters found in the area from the 
Coral Sea to the central and eastern parts of the basin during La Niña seasons favour increase of TC activity in the western part of the basin as well as in the central part.

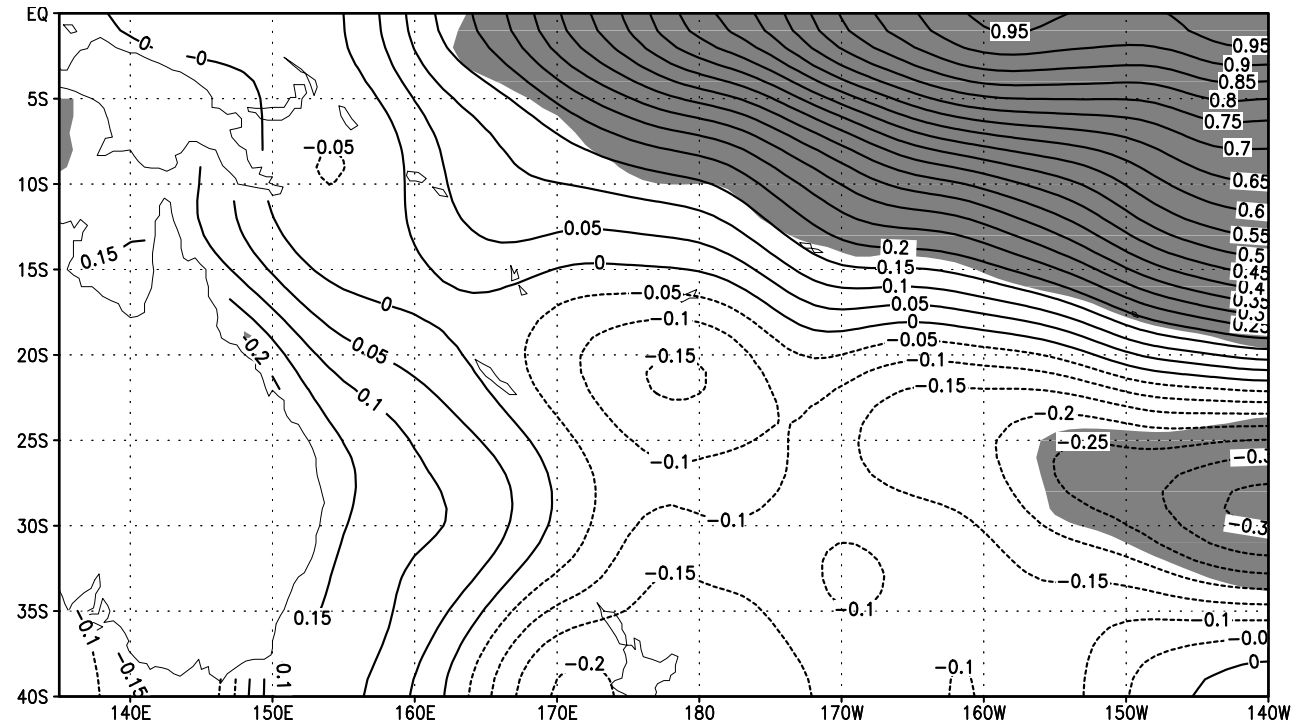

(a)

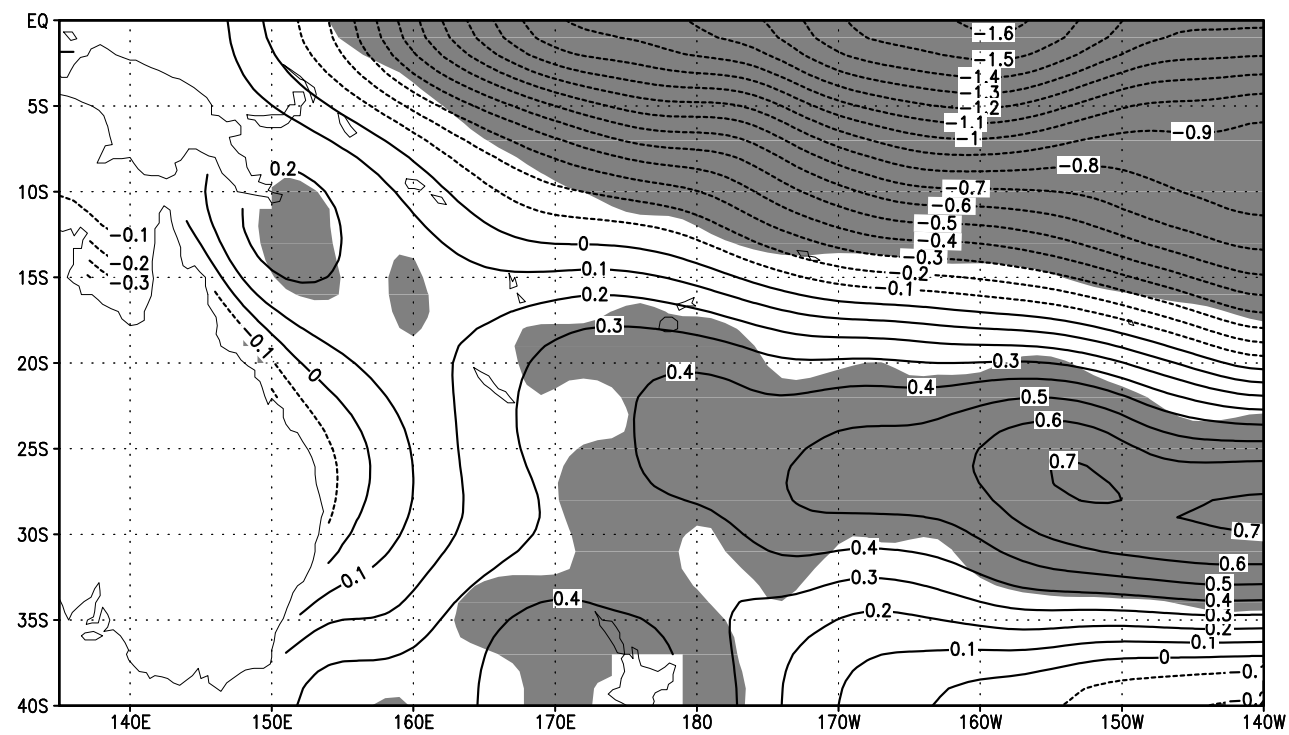

(b)

Fig. 8. SST anomalies $\left({ }^{\circ} \mathrm{C}\right)$ from November to April in the South Pacific Ocean during (a) El Niño and (b) La Niña episodes. The shades indicate areas where the statistical test is significant at the $95 \%$ level. 


\subsection{Relative humidity}

High relative humidity is one of the key factors influencing TC development as it provides sufficient moisture at the lower level and in the mid-troposphere (4 to $8 \mathrm{~km}$ ) (Gray, 1979). Geographical distribution of mid-tropospheric relative humidity at $500 \mathrm{hPa}$ level during the period from November to April has been examined in this section. Results for El Niño events are shown in Fig. 9a. A large area with negative anomalies of relative humidity is observed between the equator and about $15^{\circ} \mathrm{S}$ (Fig. 9a), but it is noticed that most of the negative anomalies did not pass the significance test except for the some areas off Western Australia and over parts of Indonesia. The areas of negative anomalies of relative humidity are collocated with the areas of relatively weak anomalies of SSTs, which can additionally contribute to decreased TC activity in the eastern part of the basin (about $10^{\circ} \mathrm{S}, 95^{\circ} \mathrm{E}$ in Fig. 4a) during El Niño seasons.

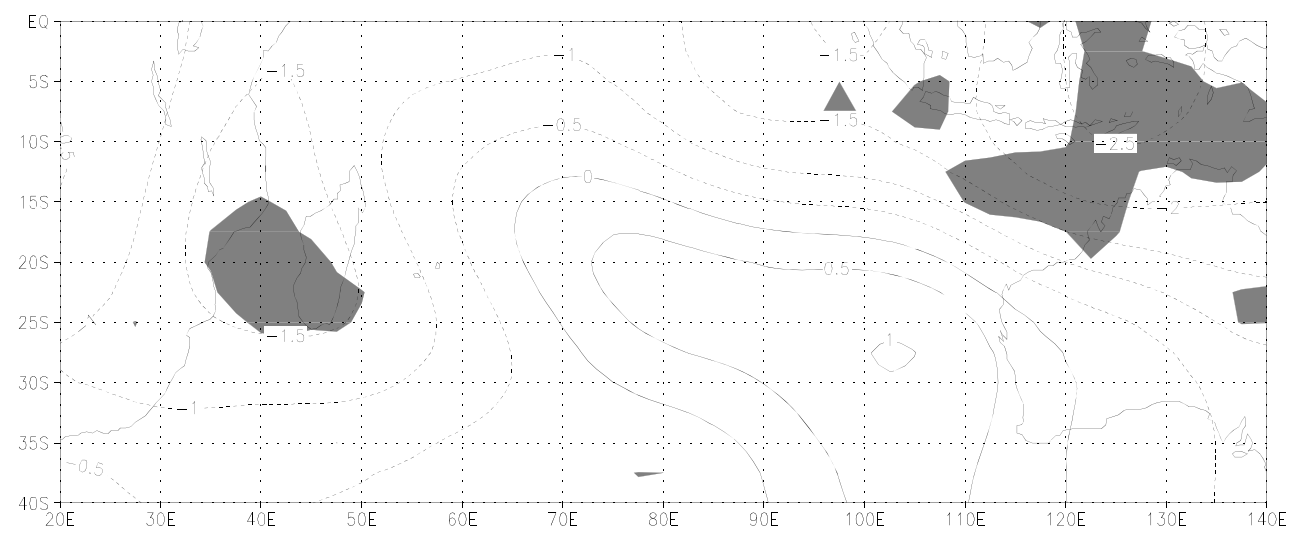

(a)

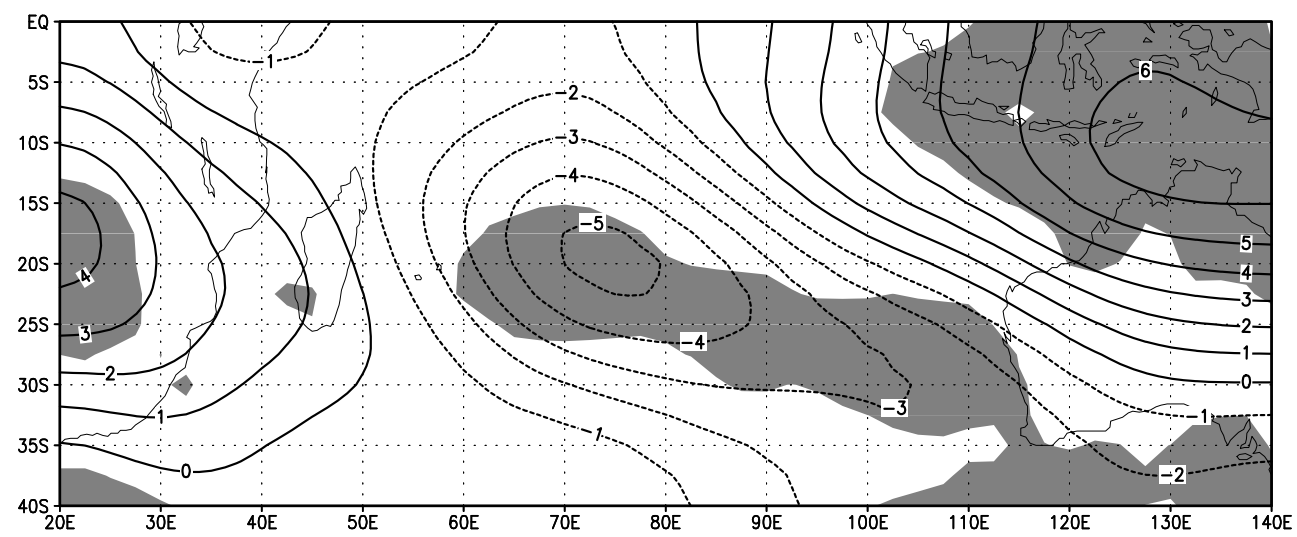

(b)

Fig. 9. Relative humidity anomalies (\%) at 500hPa over the South Indian Ocean for (a) El Niño and (b) La Niña episodes. The shades indicate areas where the statistical test is significant at the $95 \%$ level. 
Comparing results presented in Figs. 9a (El Niño) and 9b (La Niña), significant relative humidity decrease in the central part of the basin (about $70^{\circ} \mathrm{E}$ ) was found during La Niña seasons, which is consistent with the decreased TC activity over this area evident from comparing Fig. 4a and Fig. 4b. During La Niña seasons, there is a large area with positive anomalies of relative humidity over the equatorial and tropical regions of the northwest of Australia and Indonesia from $85^{\circ} \mathrm{E}$ to $140^{\circ} \mathrm{E}$, with another positive anomaly area to the west of Madagascar (Fig. 9b), and large area for negative anomalies over the central part (around $20^{\circ} \mathrm{S}, 75^{\circ} \mathrm{E}$ ) of the basin. To the northwest of Australia, positive relative humidity anomalies and warmer SSTs both contributes towards increased TC activity during La Niña seasons.

Relative humidity anomalies at $500 \mathrm{hPa}$ over the SPO during warm and cold phases of the ENSO are shown in Fig. 10a and 10b, respectively. During El Niño years, an area of positive relative humidity anomalies is located east of dateline between the equator and about $10^{\circ} \mathrm{S}$, which is a classical pattern for El Niño events (Fig. 10a). A large drier zone of relative humidity is observed southwest to the positive anomalies, with a minimum centre in the central part of the basin. Over the Coral Sea, significant negative anomalies are also observed, where TC activity is weaker. During La Niña events, the geographical distribution of relative humidity anomalies is the opposite; they are positive over a large area extending from the Coral Sea to the central part of the basin, significant at 95\% level (Fig. 10b), corresponding well with the increased TC activities over the western and central parts of the basin (Fig. 6b).

\subsection{Vertical wind shear}

The vertical wind shear plays an important role in tropical cyclogenesis and development: strong vertical wind shear inhibits tropical cyclogenesis, while weak vertical shear favours TC genesis and development (DeMaria 1996, Maloney and Hartmann 2000, Zehr 2003). It is well known that vertical wind-shear variations can have a significant impact on the interannual variability of TC activity in the Northern Hemisphere (e.g., Gray 1984).

The vertical wind shear is defined here as the difference of magnitudes between the zonal wind fields at $200 \mathrm{hPa}$ and $850 \mathrm{hPa}$. Results of analysis are shown for El Niño and La Niña seasons in Fig. 11a and 11b, respectively. The vertical wind shear over the whole basin is slightly weaker during El Niño seasons than that during La Niña seasons, in particular over the central and eastern parts of the basin. In general, wind shear is relatively weak in the near-equatorial area. Also, in the western part of the basin (west of $70^{\circ} \mathrm{E}$ ) the wind shear is weaker than in the eastern part of the basin during both warm and cold ENSO episodes. Changes in this environmental factor are not easily interpreted in order to explain observed changes in TC activity.

During the ENSO warm phase (Fig. 12a), a zone of relatively weak vertical wind shear $(<8$ $\mathrm{ms}^{-1}$ ) located over most of the equatorial and tropical areas of the SPO basin with the contour of $10 \mathrm{~ms}^{-1}$ located at $13^{\circ} \mathrm{S}$ to $14^{\circ} \mathrm{S}$ in the western and central part of the basin. During the ENSO cold phase (Fig. 12b), the zone of relatively weak wind shear moves westwards with a minimum centre at about $160^{\circ} \mathrm{E}$ to $175^{\circ} \mathrm{E}$. The contour of $10 \mathrm{~m}^{-1}$ moves southwards to about $15^{\circ} \mathrm{S}$ to $20^{\circ} \mathrm{S}$ across the whole basin. This spatial distribution of vertical wind shear contributes to increased TC activity over the area west of the dateline and shifting area of enhanced cyclogenesis and TC development closer to Australia during La Niña seasons. 


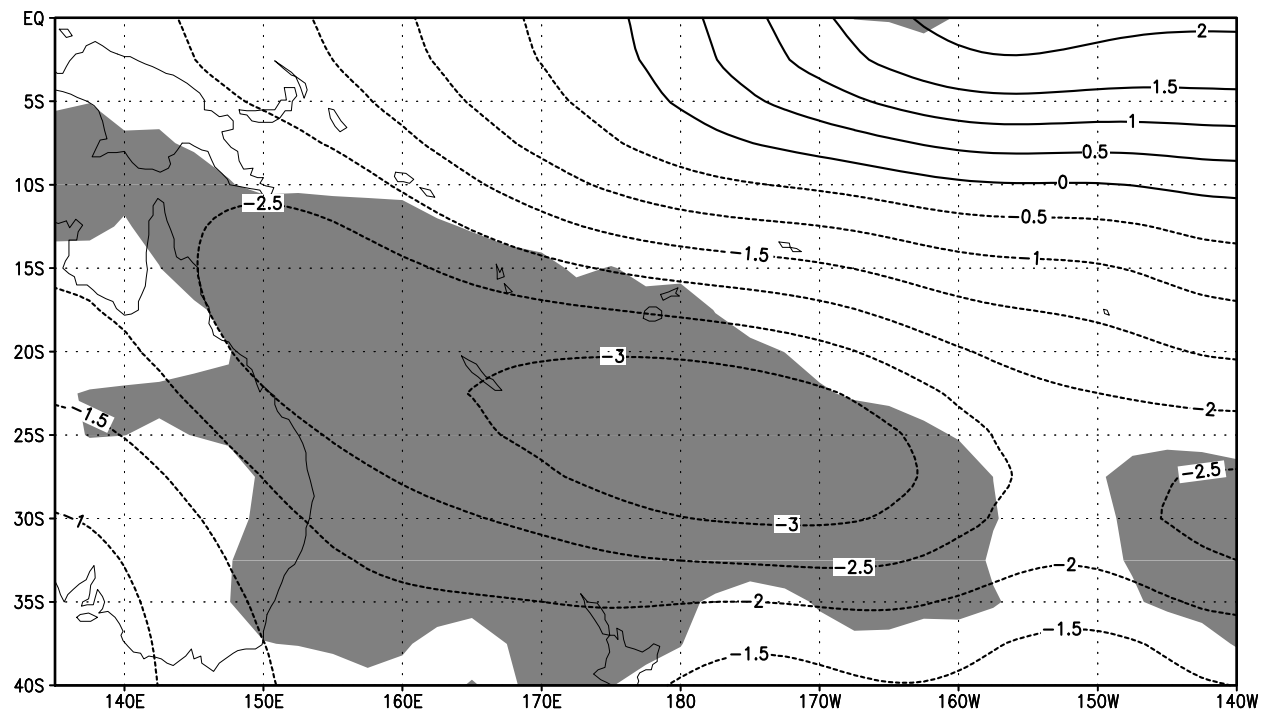

(a)

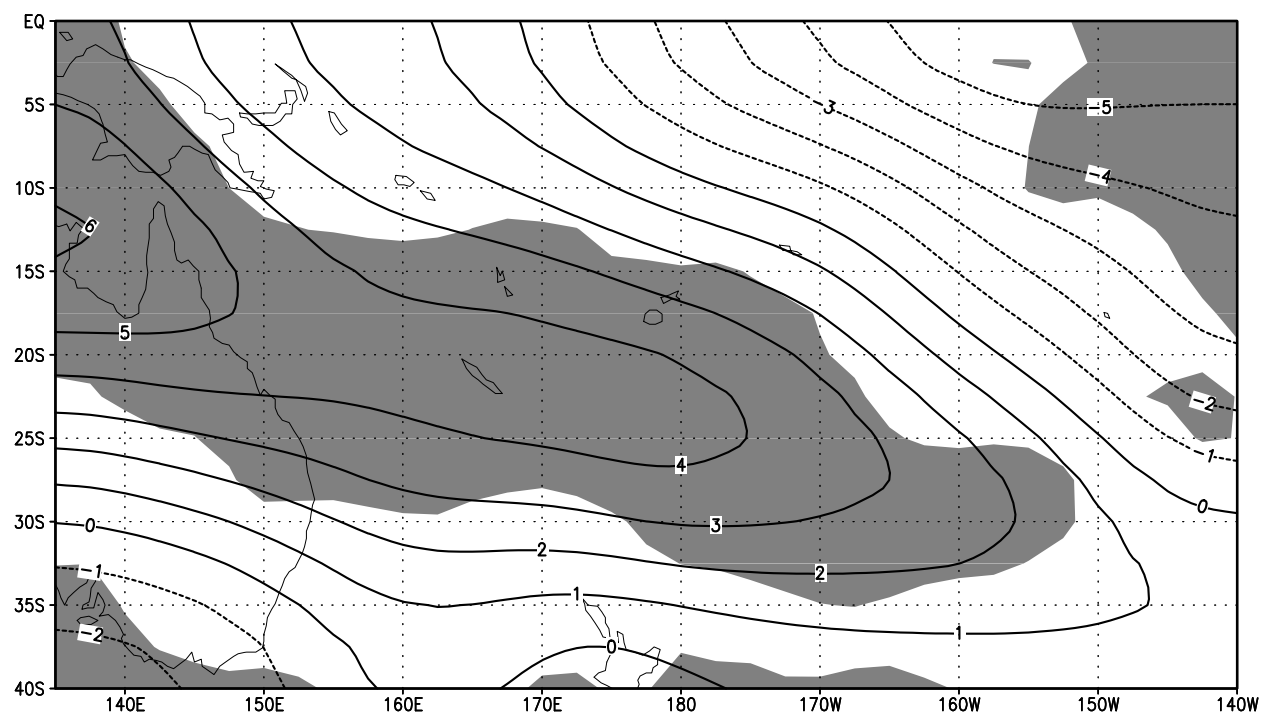

(b)

Fig. 10. Relative humidity anomalies (\%) at 500hPa over the South Pacific Ocean for (a) El Niño and (b) La Niña episodes. The shades indicate areas where the statistical test is significant at the $95 \%$ level. 


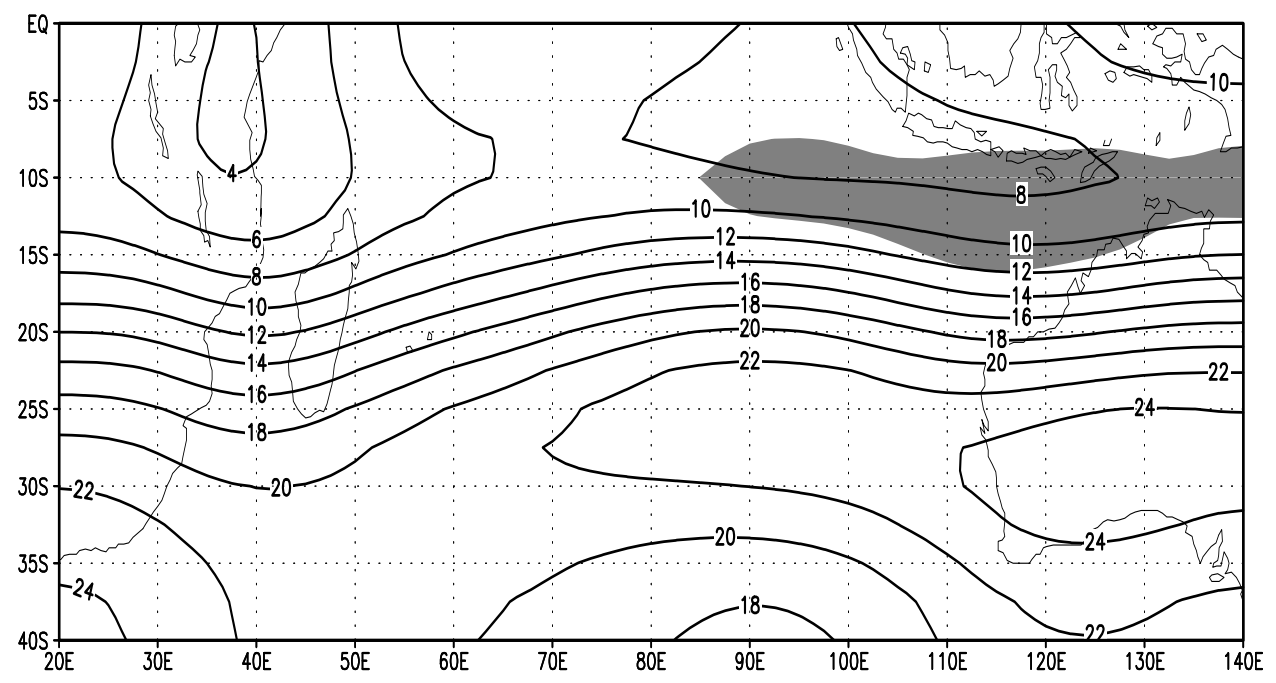

(a)

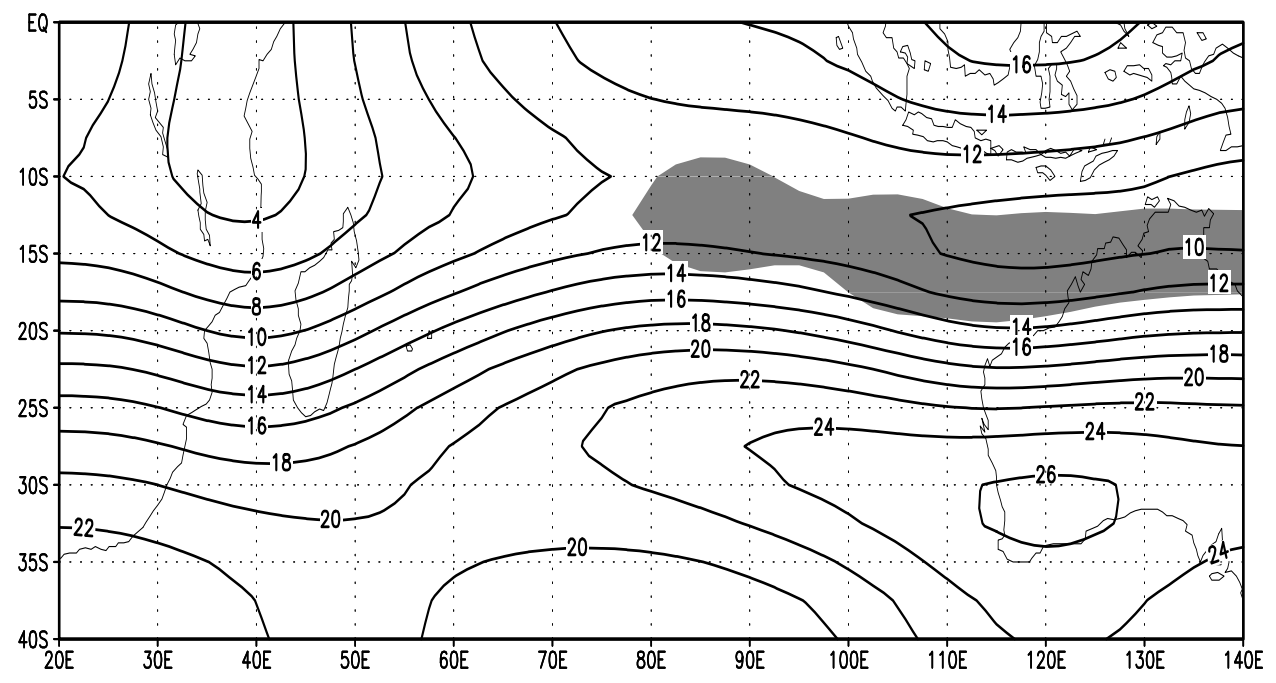

(b)

Fig. 11. Zonal wind shear $\left(\mathrm{U}_{200}-\mathrm{U}_{850}\right)\left(\mathrm{m} \mathrm{s}^{-1}\right)$ over the South Indian Ocean for (a) El Niño and (b) La Niña episodes. The shades indicate areas where the statistical test is significant at the 95\% level. 


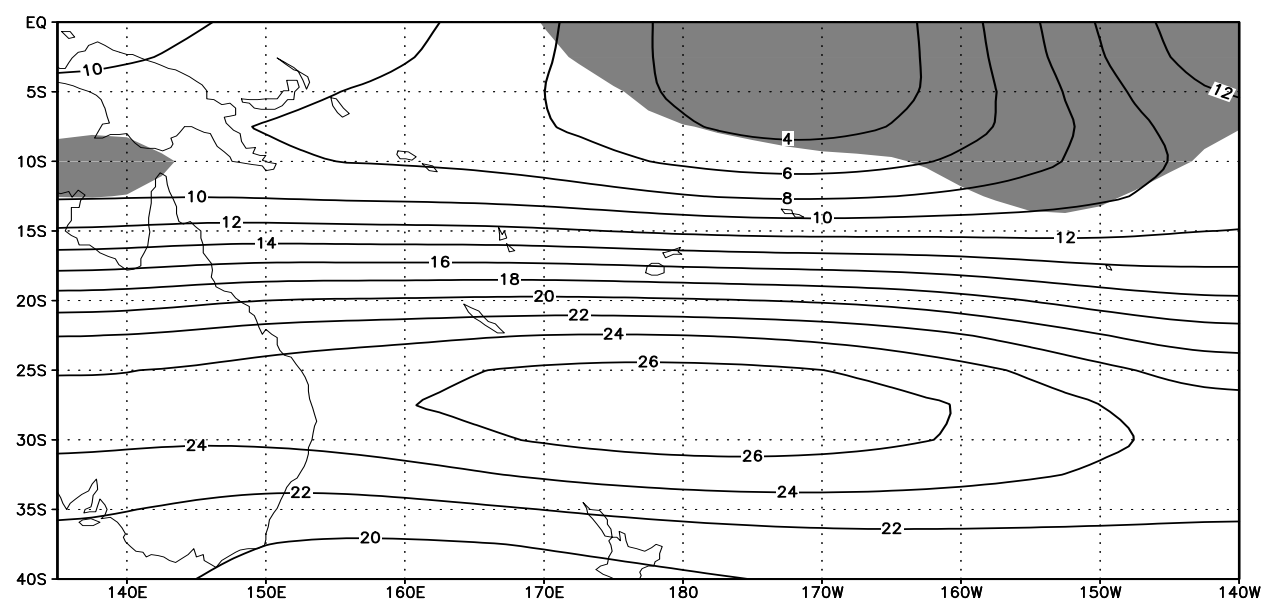

(a)

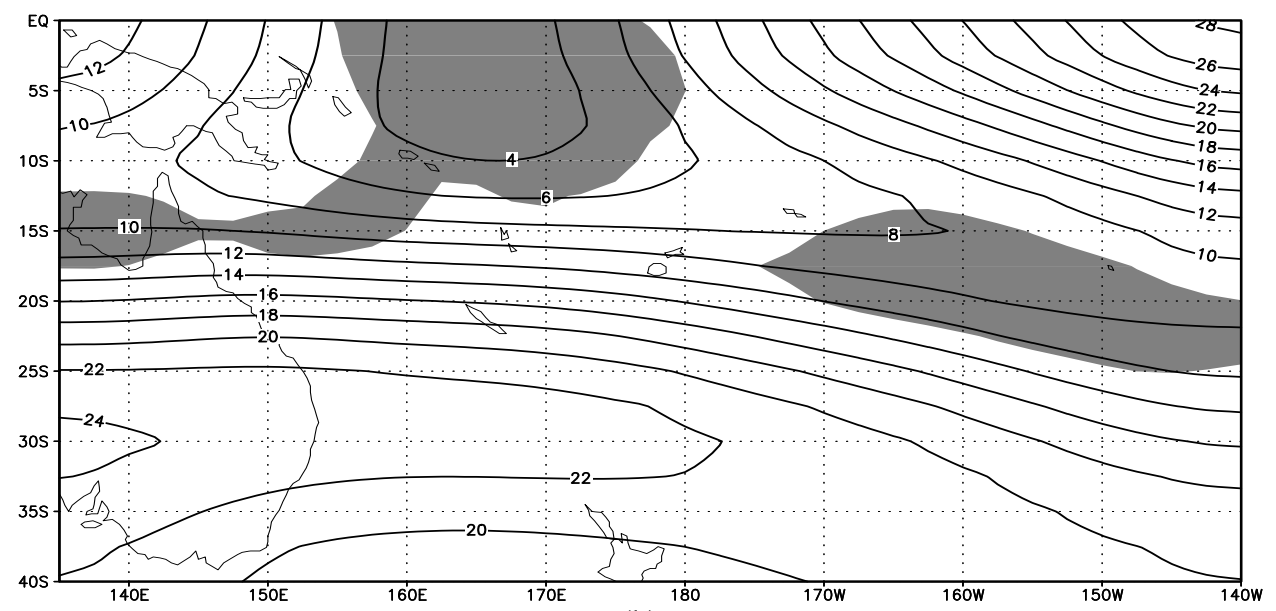

(b)

Fig. 12. Vertical wind shear $\left(\mathrm{U}_{200}-\mathrm{U}_{850}\right)\left(\mathrm{m} \mathrm{s}^{-1}\right)$ over the South Pacific Ocean for (a) El Niño and (b) La Niña episodes. The shades indicate areas where the statistical test is significant at the $95 \%$ level.

\subsection{Vorticity}

The vorticity anomalies at 0.995 sigma level (surface level) from November to April during El Niño seasons over the SIO are shown in Fig. 13a. Large area of positive (anticyclonic) vorticity anomalies at [about $5-15^{\circ} \mathrm{S}, 70-135^{\circ} \mathrm{E}$ ] which extends from the central part of the basin to the northwest coast of Australia is evident in Fig. 13a. However, centred around $\left[25^{\circ} \mathrm{S}, 65^{\circ} \mathrm{E}\right]$, there is a large area of negative (cyclonic) vorticity anomalies which are more favourable to tropical cyclogenesis. During El Niño seasons, the areas to the north of $15^{\circ} \mathrm{S}$ and east of $70^{\circ} \mathrm{E}$, are not favourable (in terms of vorticity impacts) to the TC genesis in comparison to the rest of the basin. 


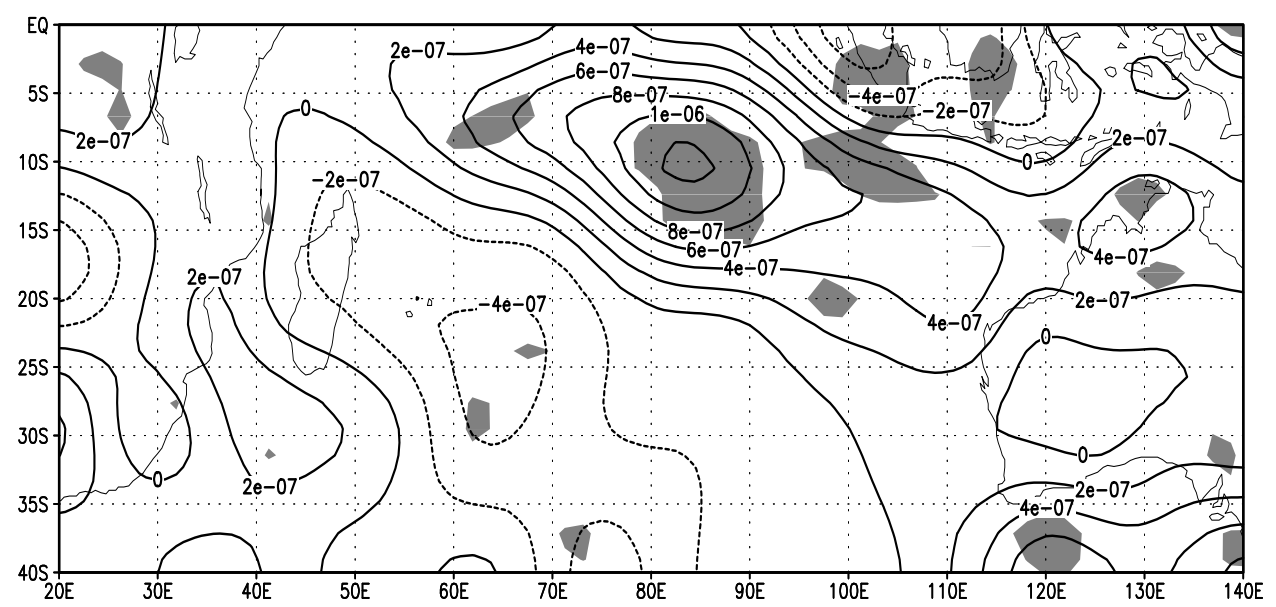

(a)

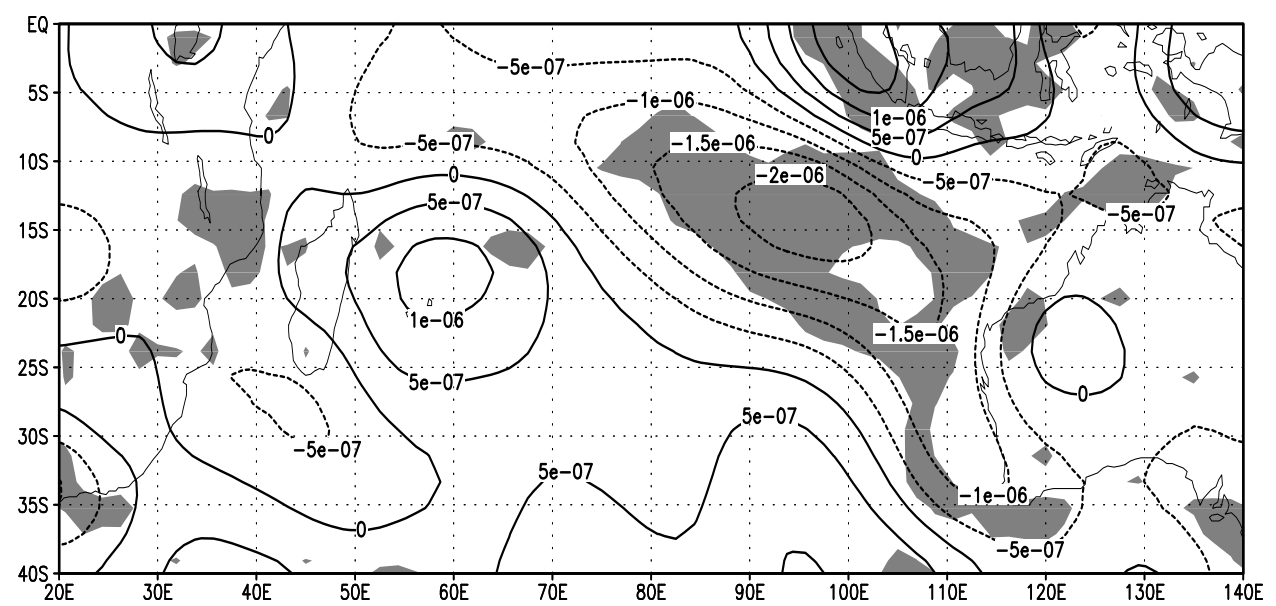

(b)

Fig. 13. Vorticity anomalies at 0.995 sigma level $\left(\mathrm{s}^{-1}\right)$ over the South Indian Ocean for (a) El Niño and (b) La Niña episodes. The shades indicate areas where the statistical test is significant at the $95 \%$ level.

During La Niña seasons, negative (cyclonic) vorticity anomalies over the tropical areas of the central and eastern parts of the basin (Fig. 13b) replace the anticyclonic vorticity anomalies observed in this area during El Niño seasons (Fig. 13a). It additionally contributes to increase in cyclone activity in the eastern part of the basin during La Niña seasons. In the western part, cyclonic vorticity anomalies are also observed between Madagascar and mainland Africa.

Vorticity anomalies at 0.995 sigma level during warm and cold phases of the ENSO over the SPO are shown in Fig. 14a and 14b, respectively. For El Niño seasons, negative vorticity anomalies dominate over the near-equatorial areas, with a minimum centre located at about 
$10^{\circ} \mathrm{S}$ to $175^{\circ} \mathrm{W}$, and positive anomalies of vorticity are observed to the south over latitudes from about $15^{\circ} \mathrm{S}$ to $35^{\circ} \mathrm{S}$ across the whole basin (Fig. 14a). Cyclonic (negative) vorticity anomalies in the area $\left[5-15^{\circ} \mathrm{S}\right]$ favour cyclogenesis in the near-equatorial areas and contribute to increased TC activity in the eastern part of the basin in El Niño seasons. For La Niña seasons, spatial distribution of vorticity anomalies is the opposite: positive anomalies are located over the near-equatorial areas and negative anomalies are observed to the south (Fig. 14b). This geographical distribution of vorticity anomalies contributes to restraining TC genesis in areas close to the equator but promotes cyclogenesis in the Australian region in La Niña seasons.

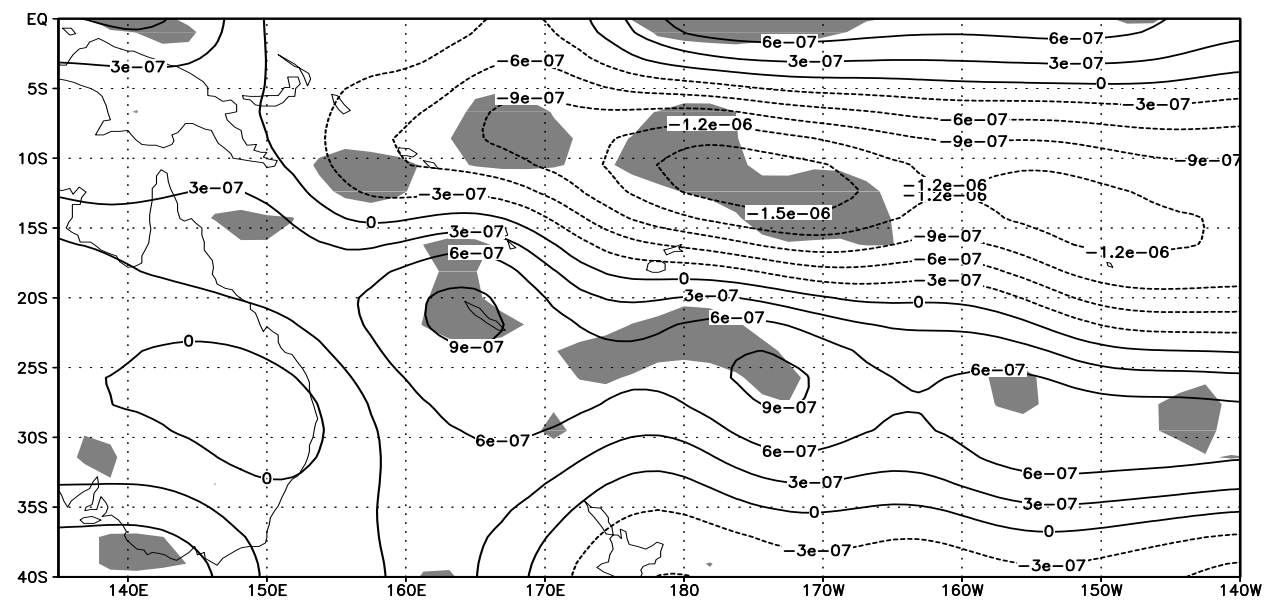

(a)

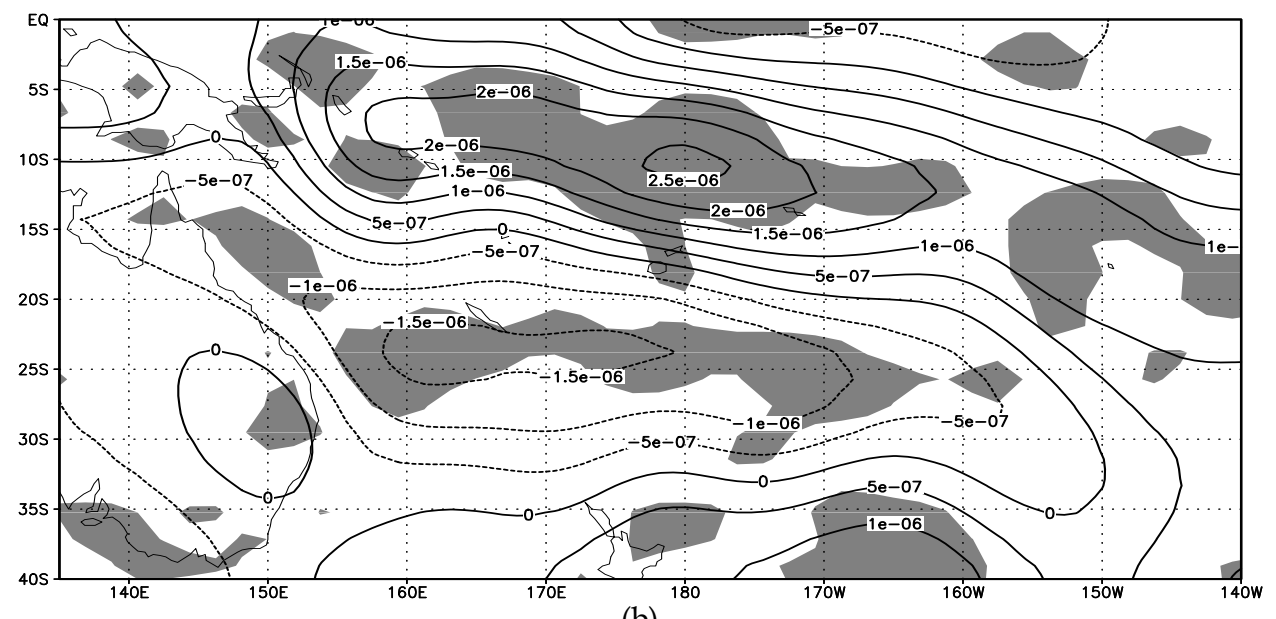

(b)

Fig. 14. Vorticity anomalies at 0.995 sigma level $\left(\mathrm{s}^{-1}\right)$ over the South Pacific Ocean for (a) El Niño and (b) La Niña episodes. The shades indicate areas where the statistical test is significant at the $95 \%$ level. 


\subsection{Discussion and summary}

ENSO is a coupled ocean-atmosphere phenomenon and changes in oceanic conditions associated with El Niño and La Niña events are coupled with changes in atmospheric circulation. During the ENSO warm phase, an El Niño event, changes in large-scale environmental conditions such as weakening the Walker circulation (this manifests in weakening the easterly trade winds, rise in air pressure over the Indian Ocean, Indonesia and Australia and fall in air pressure over the central and eastern Pacific Ocean) and displacing warm water in the Pacific (i.e. cooling water in the western Pacific and warming water in the central and eastern equatorial Pacific) occur. During the ENSO cold phase, a La Niña event, the trade winds strengthen, warmer water accumulates in far western Pacific and cold pool in the eastern Pacific intensifies resulting in equatorial SSTs being cooler than climatological average.

In this analysis, changes in tropical cyclogenesis over the South Indian and South Pacific Oceans related to changes in large-scale environmental factors associated with the warm and cold phases of the ENSO phenomenon have been investigated. The physical mechanism by which changes in TC activity are related to the environment has been explored. Warm equatorial water provides thermal energy necessary for TC genesis (Gray 1979) and therefore variation in geographical distribution of SSTs related to changes of the ENSO phases was examined. Large-scale vertical motion which provides convection was examined through analysing relative humidity in mid-troposphere. Positive (negative) anomalies of midtropospheric relative humidity which characterize upward (downward) large-scale vertical motion enhance (reduce) TC genesis. The negative effect of vertical wind shear on TC genesis and intensification is well documented (Gray 1968, Merrill 1988). As ENSO affects the strength of easterly and westerly winds in near-equatorial area, these variations in zonal flow are associated with changes in low-level relative vorticity fields. Consequently, influence of the key environmental factors such as SSTs, relative humidity in mid-troposphere, vertical wind shear and lower tropospheric vorticity on TC genesis have been examined.

Over the SIOcean, TC genesis occurs over most of the basin with maximum cyclogenesis in the area $\left[5-15^{\circ} \mathrm{S}, 60-130^{\circ} \mathrm{E}\right]$. In the central part of the basin, only a small number of cyclogenesis events are found south of $15^{\circ} \mathrm{S}$. However, in the eastern part of the basin (east of $105^{\circ} \mathrm{E}$ ) maximum TC genesis is located in the area between $10^{\circ} \mathrm{S}$ and $20^{\circ} \mathrm{S}$, and in the western part of the basin (between African coast and $60^{\circ} \mathrm{E}$ ) area favourable to TC genesis occupies range of latitudes from $10^{\circ} \mathrm{S}$ to $25^{\circ} \mathrm{S}$.

During El Niño episodes, TC genesis is above climatology over the western part of the basin and below climatology over the eastern part, while during La Niña episodes it is the opposite. TC genesis also tends to occur further away from the equator during La Niña episodes compared to El Niño episodes.

In the eastern part of the basin near the coast of Western Australia, enhanced TC activity is observed in La Niña seasons compared to El Niño episodes. A number of large-scale environmental factors contribute to increase in cyclogenesis. During El Niño episodes, positive (anticyclonic) vorticity anomalies, negative relative humidity anomalies, and relatively weak positive anomalies of SSTs are observed over this area; all these factors contribute to suppressing TC genesis. On the contrary, negative (cyclonic) vorticity anomalies, positive relative humidity anomalies, and positive anomalies of SSTs observed during La Niña episodes enhance cyclogenesis in this area. 
Positive vorticity anomalies contribute to inhibiting TC cyclogenesis in the western part of the basin during La Niña episodes. Negative SSTAs in the central part of the basin (around $\left.70^{\circ} \mathrm{E}\right)$ during La Niña episodes additionally reduce TC genesis in this part the SIO in La Niña seasons compared to El Niño seasons.

In the SPO, tropical cyclogenesis is observed over the range of longitudes between $135^{\circ} \mathrm{E}$ and $120^{\circ} \mathrm{W}$. During El Niño episodes, area of above climatology TC genesis is located in the eastern part of the basin east of the line $\left[10^{\circ} \mathrm{S}, 165^{\circ} \mathrm{E}-20^{\circ} \mathrm{S}, 175^{\circ} \mathrm{E}\right]$. During La Niña episodes, TC genesis occurs further away from the equator compared to El Niño episodes, and TC activity is displaced to the western part of the basin closer to Australia. In general, southwest (northeast) shift of points of cyclogenesis during La Niña (El Niño) episodes is observed.

During El Niño (La Niña) episodes, positive (negative) SSTAs in the eastern part of the basin and in the near-equatorial region promote (inhibit) TC genesis and development in the eastern part of the basin and contribute to displacing area preferable for TC genesis closer to (away from) the equator. During La Niña episodes, warmer waters in the southwestern part of the basin favour increase of TC activity in the western part of the basin, closer to Australia. The variations of the relatively humidity fields at $500 \mathrm{hPa}$ which consistent with variations in SSTs contribute significantly to changes in cyclogenesis over the basin.

Cyclonic vorticity anomalies are another factor which favours increased TC activity in the central and eastern part of the basin in El Niño episodes. In La Niña episodes, anticyclonic vorticity anomalies located over the near-equatorial region contribute to decrease in TC genesis in the area close to the equator while cyclonic vorticity anomalies located between latitudes around $15-25^{\circ} \mathrm{S}$ contribute to increase in TC activity in the Australian region.

Relatively low vertical wind shear observed in the central equatorial and tropical areas of the basin also enhances TC activity in the central and eastern part of the basin in El Niño episodes. During La Niña episodes, low vertical wind shear west of $180^{\circ}$ enhances cyclogenesis in areas closer to Australia.

This analysis demonstrates that over the whole SIO basin, the changes in geographical distribution of relative humidity and vorticity are primary contributors to the variations in TC genesis related to the ENSO phenomenon. Positive anomalies of SSTs observed during La Niña seasons in the eastern part of the basin also contribute to enhanced cyclogenesis near the Western Australia.

In the Pacific, large-scale environmental changes associated with the ENSO (i.e. changes in near-equatorial SSTs and the Walker Circulation) significantly affect TC genesis. Changes in geographical distribution of relative humidity and vorticity are primary factors influencing tropical cyclogenesis over the entire South Pacific, with changes in SSTs and vertical wind shear additionally favouring enhanced TC activity in the eastern (western) part of the basin during El Niño (La Niña) years.

The general conclusions of Camargo et al. (2007) and Kuleshov et al. (2009a) that midtropospheric relative humidity and vertical wind shear are important contributors to variation in tropical cyclogenesis in the basins of the $\mathrm{SH}$; however the key role of vorticity and additional contribution of changes in SSTs in the South Indian and the South Pacific Oceans has been also demonstrated. 
During El Niño events TC activity in the South Pacific is displaced away from the Australian coast further eastward (Gray 1988, Basher and Zheng 1995) and it reports that relative humidity and vorticity are the key factors of the South Pacific TC environment.

In summary, using the data from recently developed SHTC archive, changes in tropical cyclogenesis over the South Indian and South Pacific Oceans related to changes in the ENSO phases have been investigated and significant variations in geographical distribution of areas of enhanced TC genesis have been identified. To explain these changes, large-scale environmental factors which influence TC genesis and development such as sea surface temperature, relative humidity in mid-troposphere, vertical wind shear and lower tropospheric vorticity have been examined. In the SIO, reduction of TC genesis in the western part of the basin and its increase in the eastern part as well as displacement of the area favourable for TC genesis further away from the equator during La Niña events compared to El Niño events can be explained by changes in geographical distribution of relative humidity and vorticity across the basin as primary contributors; positive anomalies of SSTs observed during La Niña seasons in the eastern part of the basin also contribute to enhanced cyclogenesis near the Western Australia. In the SPO, changes in geographical distribution of relative humidity and vorticity appear to be the key large-scale environmental factors responsible for enhanced TC genesis in the eastern (western) part of the basin as well as for the northeast (southwest) shift of points of cyclogenesis during El Niño (La Niña) events, with vertical wind shear and SSTs as additional contributing environmental factors.

\section{Spatial variability of tropical cyclones}

Using the best track data from the SH TC archive, various aspects of TC climatology for the SIO and SPO were examined in detail. In particular, Figure 15 shows the climatology of TC days for the entire period of available data (1969/1970 to 2009/2010), and Figure 16 shows the climatology of TC genesis for the period of available central pressure data (1981/1982 to 2009/2010) (Dowdy and Kuleshov, 2011). The region of TC activity stretches from the east coast of Africa throughout the SIO and into the eastern regions of the SPO. Numerous spatial features are apparent in the climatological fields of TC days and TC genesis, broadly consistent with the results of other previous studies (e.g. Kuleshov et al. 2008, 2009a, 2010b).

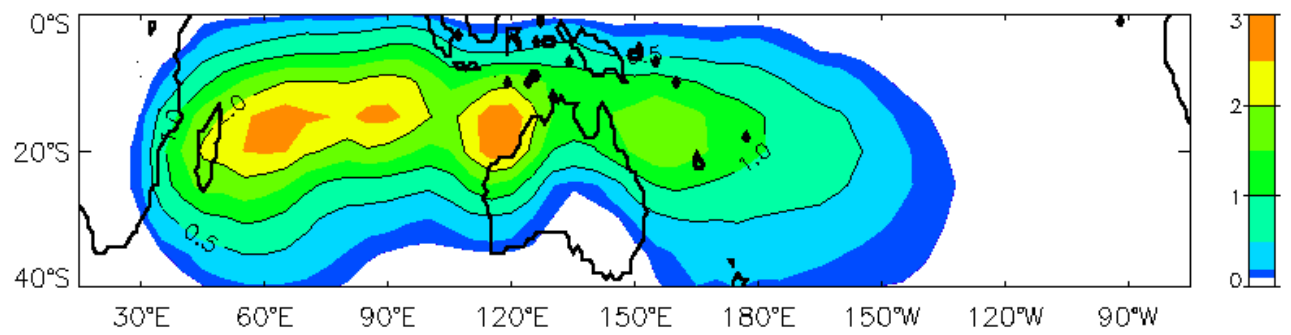

Fig. 15. Average annual number of TC days for the Southern Hemisphere.

As it was described in previous sections, ENSO phenomenon has significant impact on TC spatial variability. Based on the above considerations, the SHTC data were stratified between warm and cold ENSO phases to construct maps of average annual number of TCs in El Niño (Fig. 17) and La Niña (Fig. 18) years (Kuleshov et al., 2008). A comparison of the 
maps demonstrates substantial shifts in the positions of maximum TC occurrences as well as changes in the intensity of the occurrence maxima. On average, around 25 and 29 TCs annually occur in the SH during El Niño and La Niña years, respectively. In general, TC activity is higher in the SIO than in the SPO. This difference is especially pronounced in La Niña years, with an average annual number of around 18 TCs (11 TCs) in the SIO (SPO).

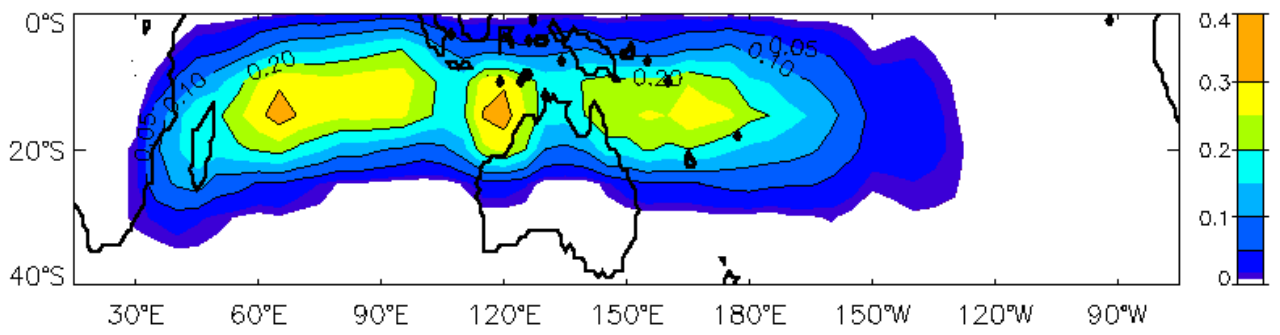

Fig. 16. Average annual number of TC genesis events for the Southern Hemisphere.

Tropical cyclogenesis (defined here as the point at which central pressure attains a threshold of $1000 \mathrm{hPa}$ or lower) in El Niño (Fig. 19) and La Niña (Fig. 20) years has also been examined (Kuleshov et al., 2008). In the SIO, one preferred area of cyclogenesis stays centred around $120^{\circ} \mathrm{E}$ during El Niño and La Niña years. However, another area of cyclogenesis which is located between $60^{\circ} \mathrm{E}$ and $85^{\circ} \mathrm{E}$ in El Niño years shifts eastwards to between $85^{\circ} \mathrm{E}$ and $105^{\circ} \mathrm{E}$ in La Niña years. In the SPO, the focus for cyclogenesis shifts eastwards in El Niño years in comparison to La Niña years, which is consistent with Basher and Zheng (1995).

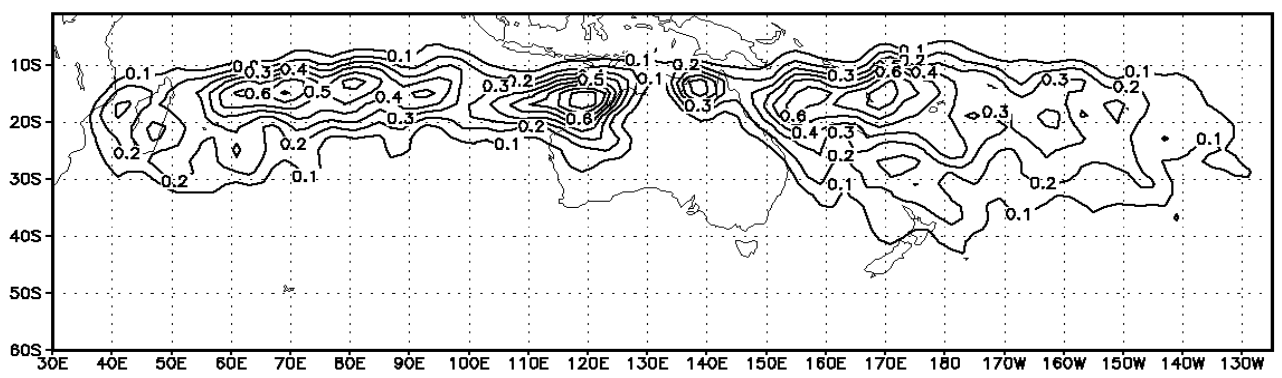

Fig. 17. Average annual number of TCs in the Southern Hemisphere in El Niño years.

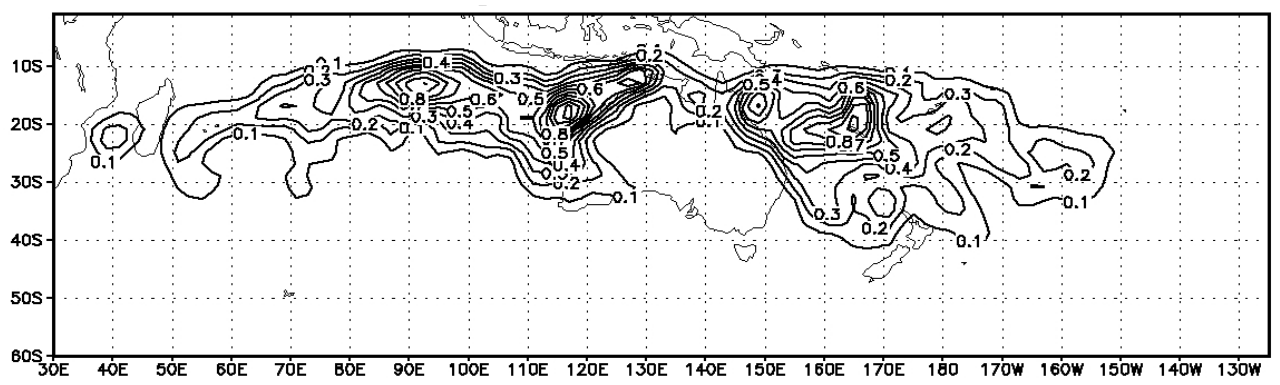

Fig. 18. Average annual number of TCs in the Southern Hemisphere in La Niña years. 


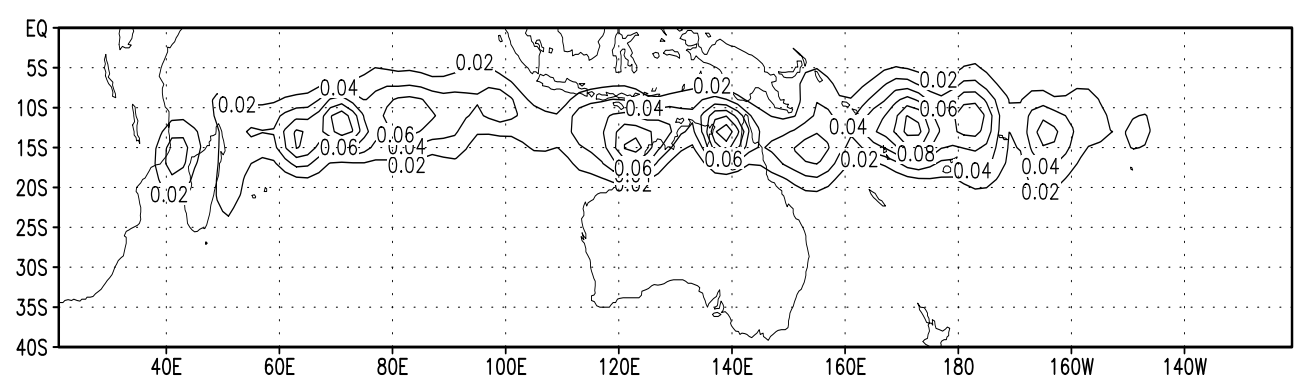

Fig. 19. Average annual number of TC genesis in the Southern Hemisphere in El Niño years.

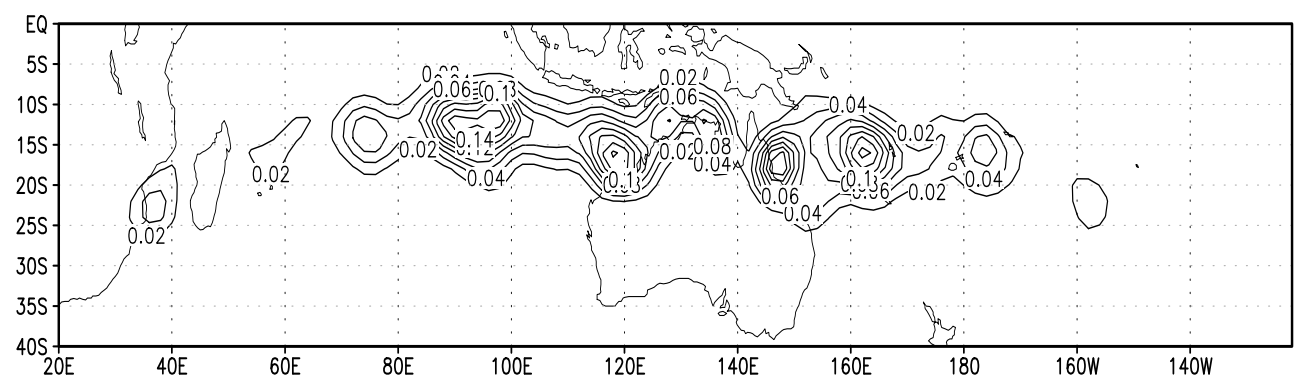

Fig. 20. Average annual number of TC genesis in the Southern Hemisphere in La Niña years.

\section{Temporal variability of tropical cyclones}

This section builds on previous work through the examination of the TC temporal variability, in particular focusing on intraseasonal variability in multiple sub-regions of each of the two TC basins of the SH. Figure 21 shows monthly distributions of TC days for the four different subregions: the west $\mathrm{SIO}$ (WSIO) for the longitude range $30-80^{\circ} \mathrm{E}$, the east $\mathrm{SIO}$ (ESIO) for the longitude range $80-135^{\circ} \mathrm{E}$, the west $\mathrm{SPO}$ (WSPO) for the longitude range $135-170^{\circ} \mathrm{E}$ and the central SPO (CSPO) for the longitude range $170^{\circ} \mathrm{E}-120^{\circ} \mathrm{W}$ (Dowdy and Kuleshov, 2011). This is shown separately for the different ENSO phases. The location of these regions is based on the results of prior studies (e.g. Kuleshov, 2003; Kuleshov et al., 2008) showing regions of strong commonality in their variation to factors such as ENSO as well as being regions of commonality in relation to the underlying climatology based on all available data. Data have only been used equatorward of $25^{\circ} \mathrm{S}$, following the results of studies such as by Sinclair (2002) who indicated that, poleward of this latitude, the average TC becomes more characteristic of a baroclinic midlatitude storm than a tropical cyclone.

The shapes of the monthly distributions are consistent with the TC season in the $\mathrm{SH}$ generally defined as from November to April, while noting that TCs can occur outside this range with a relatively lower frequency of occurrence. However, numerous features apparent in the monthly distributions are examined in detail below.

In the WSIO, there is very little difference in the monthly distributions of TC days between the different ENSO phases. Given the inherent small-scale variability expected as a result of the finite period of available data, the similarity between the different phases is quite remarkable. The vast majority of the TC days occur between November and April, with the 
highest and second highest monthly values of TC days being January and February for each of the three different phases.

In the ESIO there is an indication of a double peak (December and March) for La Niña conditions being the predominant feature. The number of TC days during these two peaks is about $50-100 \%$ higher than during the other phases of ENSO. A consistent feature between the three ENSO phases is that they all have peak TC days occurring during March.

In the WSPO, there is reasonably little difference in the monthly distributions of TC days between the different ENSO phases, with the exception of February and March for neutral conditions for which the number of TC days is higher than for the other ENSO phases. The skewness of the distribution for neutral conditions is also indicated by the peak month for TC days being March, in contrast to January and February for El Niño and La Niña conditions, respectively.

In the CSPO, the number of TC days is higher for virtually all months of the year during seasons characterized by El Niño conditions, than for the other two ENSO phases, with peak activity occurring in February. The peak activity occurs slightly earlier for La Niño conditions, in January, and slightly later for neutral conditions, in March.

Figure 22 shows monthly distributions of TC genesis, from 1981/1982 to 2009/2010. As for Figure 21, this is shown separately for the different ENSO phases and data have only been used equatorward of $25^{\circ} \mathrm{S}$. Many of the features apparent in the distributions of TC days can also be seen in the genesis distribution, although some differences are also notable.

In the WSIO, the different phases of ENSO are once again broadly similar to each other, as was the case in the monthly distributions of TC days (Figure 21). There is a slightly higher degree of variability between the different ENSO phases for TC genesis than was the case for TC days, potentially relating to the shorter time period used to produce the genesis distributions compared to the TC days distributions.

In the ESIO, a double peak in TC activity for La Niña seasons is apparent, with maxima occur in December and March. As this is consistent with the case for TC days, which is based on twice the number of La Niña seasons, this gives more weight to the likelihood that this is a real feature. The other ENSO phases are broadly similar to the case for TC days, although the peak in TC genesis for El Niño years in January is notable in that it is more comparable in magnitude to the peaks for La Niña conditions in December and March than was the case for TC days.

In the WSPO, there appears to be virtually no genesis during March for La Niña conditions, suggesting that the TC days in this region are due to TCs which have formed elsewhere and then been transported to this region. However, in the following month, more TCs form during La Niña conditions than for the other phases of ENSO. This apparently high degree of variability could potentially be related to the fact that the period of available data has relatively few La Niña seasons (eight) compared with 17 El Niño seasons and 18 neutral seasons. In addition to this, only four La Niña seasons occur during the period of available central pressure data required by the genesis definition used in this paper. It is therefore not clear whether or not small-scale features such as the variability discussed above are representative of the underlying climatology, and so they should be interpreted with a degree of caution. This highlights the need for increased availability of data, as is expected to be the case as the available period of satellite-era data grows with time. 
In the CSPO, TC genesis is clearly higher during El Niño conditions than during the other phases of ENSO. This is the same as was also the case for the monthly distribution of TC days. In general throughout the $\mathrm{SH}$, the broad similarities between the monthly distributions of TC days and the TC genesis suggests that although there may be some differences in the lifetime and transport of TCs, the overall climatologies of TC characteristics have a considerable degree of inter-relationship.
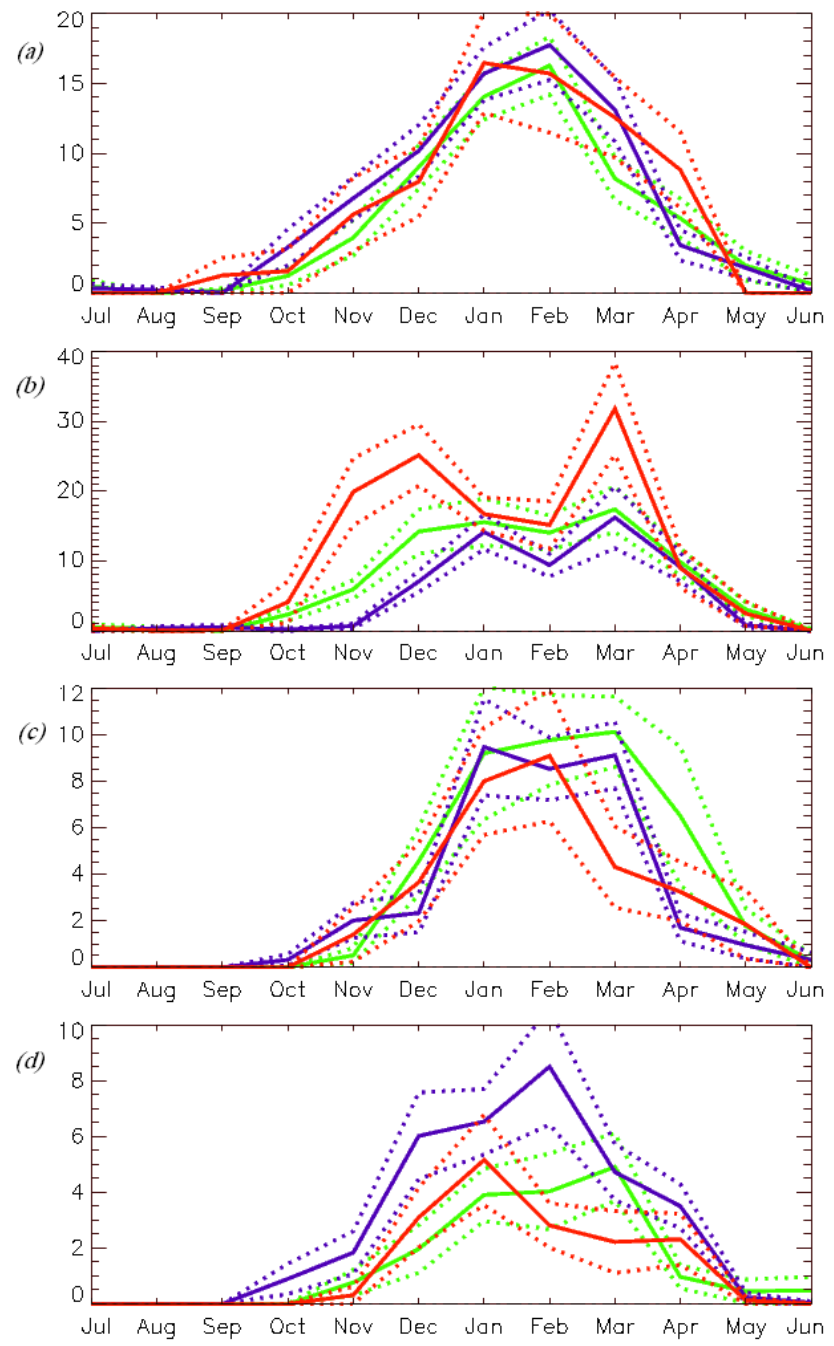

Fig. 21. Monthly distribution of TC days in the Southern Hemisphere, for neutral (green lines), El Niño (blue lines) and La Niña (red lines) phases of ENSO. This is shown for different longitudinal ranges: western $\mathrm{SIO} 30^{\circ} \mathrm{E}$ to $80^{\circ} \mathrm{E}(a)$, eastern $\mathrm{SIO} 80^{\circ} \mathrm{E}$ to $135^{\circ} \mathrm{E} \mathrm{ESIO}$ (b), western $\mathrm{SPO} 135^{\circ} \mathrm{E}$ to $170^{\circ} \mathrm{E}(c)$ and central SPO $170^{\circ} \mathrm{E}$ to $120^{\circ} \mathrm{W}(d)$. Dotted lines represent the standard error of the mean. 

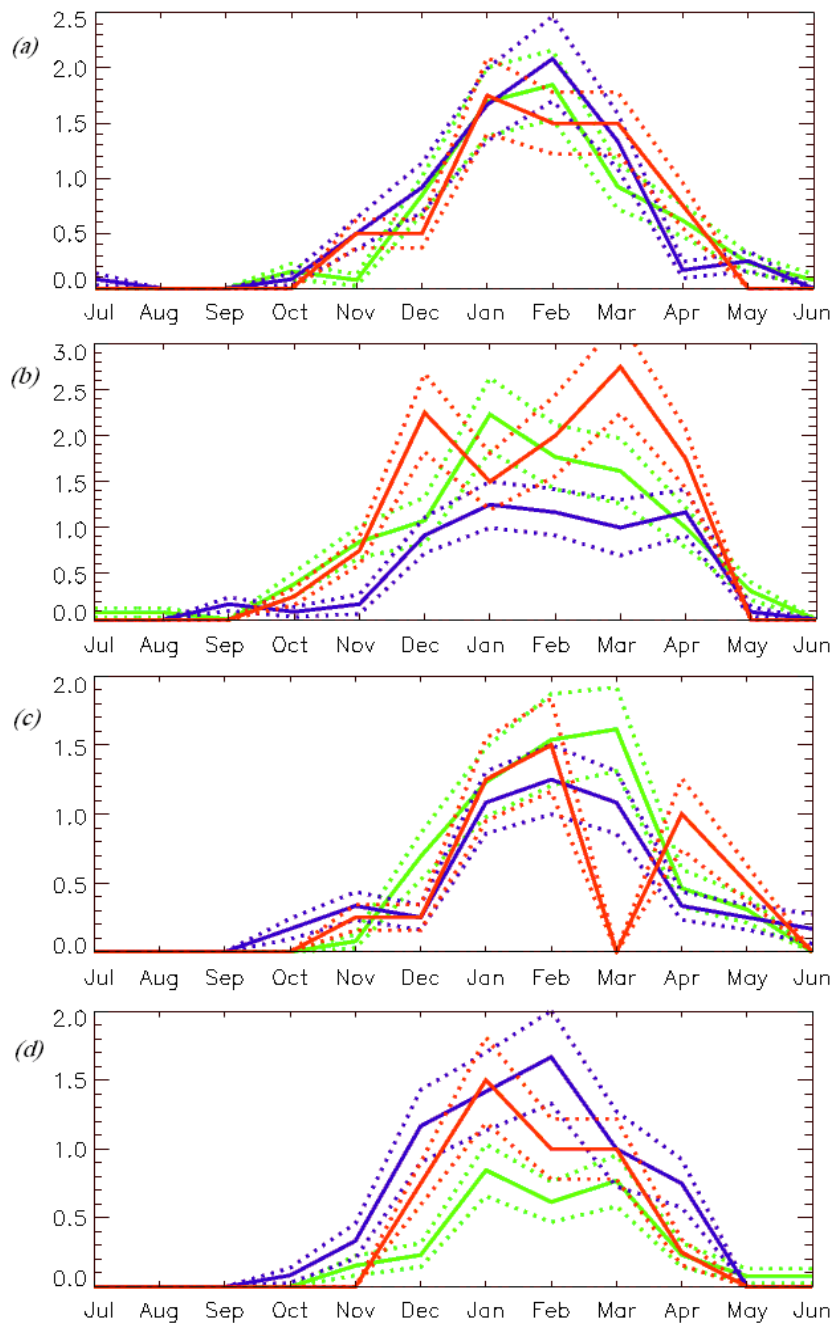

Fig. 22. As for figure 4, but for TC genesis.

\section{Trends in tropical cyclone occurrences in the Southern Hemisphere}

Trends in TC occurrences and intensity, and possible physical mechanisms for change, have been discussed widely in recent years. Webster et al. (2005) reported that the global number of very intense TCs (Saffir-Simpson categories 4 and 5) had almost doubled over recent decades. Using the TC potential dissipation index as a measure of TC activity, Emanuel (2005) arrived at similar conclusions for two of the major TC basins: the North Atlantic and the North West Pacific. Other authors have rejected these findings, mainly based on the argument that changes have been so great in observation technologies and analysis techniques that the reported changes are artificial, and not due to any actual trends (Landsea et al., 2006; Chan, 2006; Kossin et al., 2007). For the Australian region (AR) and the SH, 
trends have been reported in the number of TCs and in the proportion of very intense TCs by various authors, including Nicholls et al. (1998) and Harper et al. (2008).

It is well documented that the sea surface temperatures over the major TC basins have increased over recent decades (Knutson et al., 2006; IPCC, 2007). Theoretical and modelling studies would indicate that in response there should be a concomitant increase in the TC limiting upper intensity referred to in the literature as the maximum potential intensity (Emanuel, 1987; Holland, 1997). There is substantial discussion, however, on the magnitude of the response and whether it should be distinguishable in current data where the signal to noise ratio may be small. The small signal to noise ratio in the data is due to a number of effects including: (i) the large interannual variability of TC activity in each basin, (ii) the fact that only a small fraction of TCs actually approach their maximum potential intensity and (iii) limitations in the underlying data.

Recently, trends in activity of TCs in the SH (the region south of the equator, $30^{\circ} \mathrm{E}$ to $120^{\circ} \mathrm{W}$ ) were estimated by Kuleshov et al. (2010a) analysing the data from SHTC archive. In that study, a TC is considered a tropical system which attains minimum central pressure of 995 $\mathrm{hPa}$ or lower. The statistical significance of trends was examined based on non-parametric Monte Carlo methods and based on the test of whether a constant model, a linear model or a simple break-point model represents a best fit to the data. The purpose of this examination was to determine whether there are trends in the SH TC occurrence and intensity time series beyond what can be attributed to inter-annual variability and changes in observing procedure. The data set used is the SHTC archive which was compiled from the best track data sets of the NMHSs with WMO responsibility for TC forecasts and warnings across the $\mathrm{SH}$, in consultation with these offices. A documentation of trends in this data set thus provides baseline information for detection and attribution studies towards projections of expected changes in TC activity under global warming.

Changes in TC occurrences in the SH, the SIO and the SPO were analysed over the 26 seasons 1981/82 to 2006/07. Over this period, there are no significant trends in the annual numbers of TCs (SPO, SIO, SH) attaining an lifetime mean central pressure (LMCP) of 995 $\mathrm{hPa}$ or lower (Figure 23).

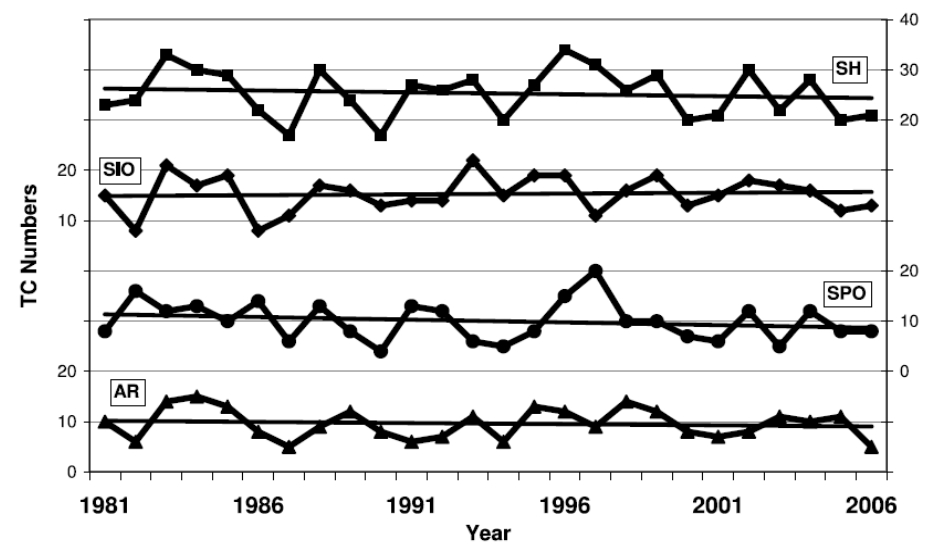

Fig. 23. Annual numbers of TCs with LMCP of $995 \mathrm{hPa}$ or lower for the $\mathrm{SH}$ (squares, right axis), SIO (diamonds, left axis), SPO (circles, right axis) and AR (triangles, left axis), 1981/82 to 2006/07 seasons, with linear trends. 
For (970 $\mathrm{hPa}$ or lower) severe TCs (Figure 24), there are no significant trends in the SIO and the $\mathrm{SH}$, although the declining trend $(-0.096 \mathrm{TCs} / \mathrm{yr})$ in the SPO is border-line significant (11\% two-tailed).

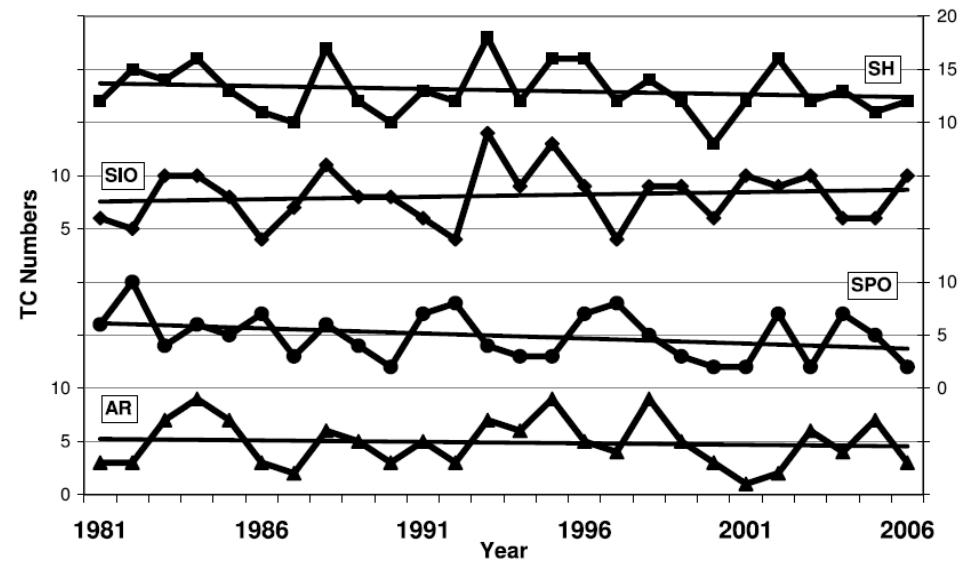

Fig. 24. Annual numbers of TCs with LMCP of $970 \mathrm{hPa}$ or lower for the $\mathrm{SH}$ (squares, right axis), SIO (diamonds, left axis), SPO (circles, right axis) and AR (triangles, left axis), 1981/82 to $2006 / 07$ seasons, with linear trends.

For the most intense (950 hPa or lower) TCs (Figure 25), there is no significant trend in the $\mathrm{SPO}$, but the trends are significant in the SIO (+0.15 TCs/yr; $1 \%$ two-tailed) and in the $\mathrm{SH}$ as a whole (+0.14 TCs/yr; 3\% two-tailed). Similar results were obtained in the annual $945 \mathrm{hPa}$ counts, but not in the $955 \mathrm{hPa}$ counts.

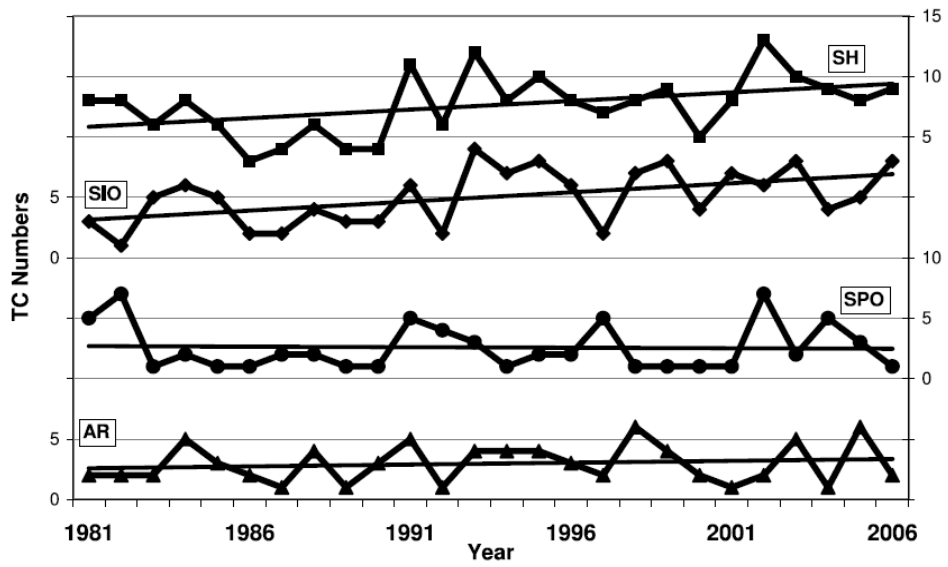

Fig. 25. Annual numbers of TCs with LMCP of $950 \mathrm{hPa}$ or lower for the $\mathrm{SH}$ (squares, right axis), SIO (diamonds, left axis), SPO (circles, right axis) and AR (triangles, left axis), 1981/82 to $2006 / 07$ seasons, with linear trends.

Analysing changes in TCs in the AR over the 26-year period (1981/82 to 2006/07), there were no significant trends in the numbers of TCs. 
Quality of historical TC data is highly important when analysing trends. Worldwide the underlying technique for determining TC intensity is the Dvorak analogue procedure based on patterns of infra-red brightness temperature (Dvorak, 1984; Velden et al., 2006). The original version of the technique, applied to visible satellite imagery, was published in 1975, with its present form, based on digital infra-red imagery, published in 1984. It was only during the mid-1980s that high-resolution multi-channel imagery became available at the AR forecast offices. In addition, supplementary data sources have increased during the past 26 years, including deployment of automatic weather stations along the Australian coastline and on small islands, and the advent of satellite-based scatterometer surface wind estimates. Various authors have discussed the potential impact of these changes on our ability to accurately determine the intensity of the more intense TCs, including Trewin (2008) and Harper et al. (2008). On a global basis, the impact of data quality on our ability to determine trends has been discussed by Landsea et al. (2006). A further compounding issue is that during forecast operations, the Dvorak technique output and the classification of TCs into intensity classes are both based on estimated sustained wind speeds. Intensity in terms of central pressure is then obtained through a wind-pressure relationship. Different windpressure relationships are in use in different forecast offices and warning centres across the SH (Knaff and Zehr, 2007; Harper et al., 2008), and there have been changes in the windpressure relationships used through the period of study. The importance of this for determination of trends is that the $\mathrm{SH}$ track archive (in its current state) contains only the derived central pressure information and does not contain the wind-speed intensity estimates used operationally.

For the Western SIO where the tracks are maintained by Météo-France (La Réunion), operational meteorologists consider the intensity data insufficiently reliable for trend estimation prior to the establishment of the RSMC La Réunion in 1993 [P. Caroff, pers. comm.]. A further improvement in data quality occurred with the beginning of geostationary satellite coverage in 1998, as a result of the launch of the MeteoSat-7 satellite (Kossin et al., 2007).

In identifying TC positions and estimating intensities, operational forecasters from Fiji and New Zealand (responsible for the eastern SPO tracks) faced similar challenges, through gradually improved observational data and understanding of TC development [S. Ready, pers. comm.]. Within the satellite era, low-resolution geostationary satellite imagery for the South Pacific (west of about $155^{\circ} \mathrm{W}$ ) became available to those forecasters from 1980 . However, only from the early 1990s, with high-resolution imagery from the GOES-West satellites now available to the RSMC Nadi (established in 1993), did the Dvorak technique become increasingly used for estimating storm intensity. Throughout the 1980s and in the first half of the 1990s, there still was a reluctance to assign intensities beyond 80 knots (central pressures below about $955 \mathrm{hPa}$ ). From the mid-1990s, as forecasters in Fiji became more proficient at the Dvorak technique, there was a greater range of intensities assigned in TC warnings. It appears that for the SPO east of $160^{\circ} \mathrm{E}$ the most reliable estimates of TC intensity start in the early 1990s, with reliable estimates of LMCP of the most intense TCs from the mid-1990s. It is likely that prior to this time the number of TCs with reported intensities below 950 or $945 \mathrm{hPa}$ in the eastern SPO is underestimated.

While some of the trends in the TC data appear to be artificial to a degree, due to changes in TC observation practices and analysis techniques as discussed above, it is possible that TC occurrences are subject to variability associated with low-frequency climate modes, such as ENSO (e.g., Kuleshov et al., 2008; Kuleshov et al., 2009a), the Indian Ocean Dipole (e.g., 
Chan and Liu, 2009) and the Pacific Decadal Oscillation (e.g., Goh and Chan, 2009), to the extent of having a noticeable impact on the trends. The inclusion of these low-frequency climate modes in the trend analysis is beyond the scope of this study, but will be a topic of further investigation.

\section{Southern Hemisphere tropical cyclone historical data portal}

To provide a user-friendly means for accessing detailed information and data on historical tropical cyclones for the Southern Hemisphere, the first version of a specialised website for disseminating results and data "Tropical Cyclones in the Southern Hemisphere" was developed in 2007. Recently, a new design for the website has been developed (Figure 26; http://www.bom.gov.au/cyclone/history/tracks/). Main features of this design are briefly presented in this section.

The new tropical cyclone website has been developed using OpenLayers platform. This allows dynamic map navigation, presenting detailed information for a selected region in the Southern Hemisphere and the display of changes in tropical cyclone intensity over the lifetime of a cyclone. The features of the new web site are presented below using tropical cyclone Heta as an example.

Tropical cyclone Heta formed on December 25, 2003 and reached a maximum intensity of $260 \mathrm{~km} / \mathrm{h}$ and an estimated pressure of $915 \mathrm{hPa}$ on January 6, 2004. Cyclone Heta caused catastrophic damage to the islands of Tonga, Niue, and American Samoa estimated at \$170 million dollars (2009 USD). Best track of tropical cyclone Heta is presented in Figure 27. In Figure 28, track of tropical cyclone Heta is displayed over the "Elevation and bathymetry" layer. Orange dots represent best track 6-hourly positions of the cyclone when its central pressure was estimated above $970 \mathrm{hPa}$ and red dots represent the cyclone's positions when pressure was estimated as equal to or below $970 \mathrm{hPa}$ (an approximate pressure threshold for severe tropical cyclones in the Southern Hemisphere).

The dynamic map navigation feature of the new web site allows one to examine the cyclone track over a selected region in detail. Dashed line connects points of the tropical cyclone best track when the system was at a stage of Tropical Depression (i.e. estimated pressure is above $995 \mathrm{hPa}$ ) and solid line connects the points when the storm attained Tropical Cyclone intensity (a threshold of $995 \mathrm{hPa}$ or below is selected for display purposes). Users can obtain information about characteristics of the tropical cyclone at particular location by clicking on a dot point. As a result, the following information is displayed: tropical cyclone name, geographical coordinates of the selected position, time and intensity in terms of an estimated value of pressure in hectopascals.

Other features of the website include displaying multiple tropical cyclone tracks to satisfy users' requirements to present cyclone tracks over the whole tropical cyclone season, or a number of seasons, and enabling a down-load facility. Specifically, "Tropical Cyclone Track Details" feature allows users to display tropical cyclone data for a selected cyclone (date and time, latitude and longitude, and intensity in terms of central pressure) in a separate window. The "Report on Specific Location" feature allows users to display tracks for cyclones crossing within specified distance (e.g. within a radius of 50, 100, 200 and $400 \mathrm{~km}$ ) from a specified position. The specified position can be defined as a point with specific geographical coordinates (e.g. $12.42^{\circ} \mathrm{S} 130.89^{\circ} \mathrm{E}$ ) or as a location selected from a list (e.g. Darwin). 


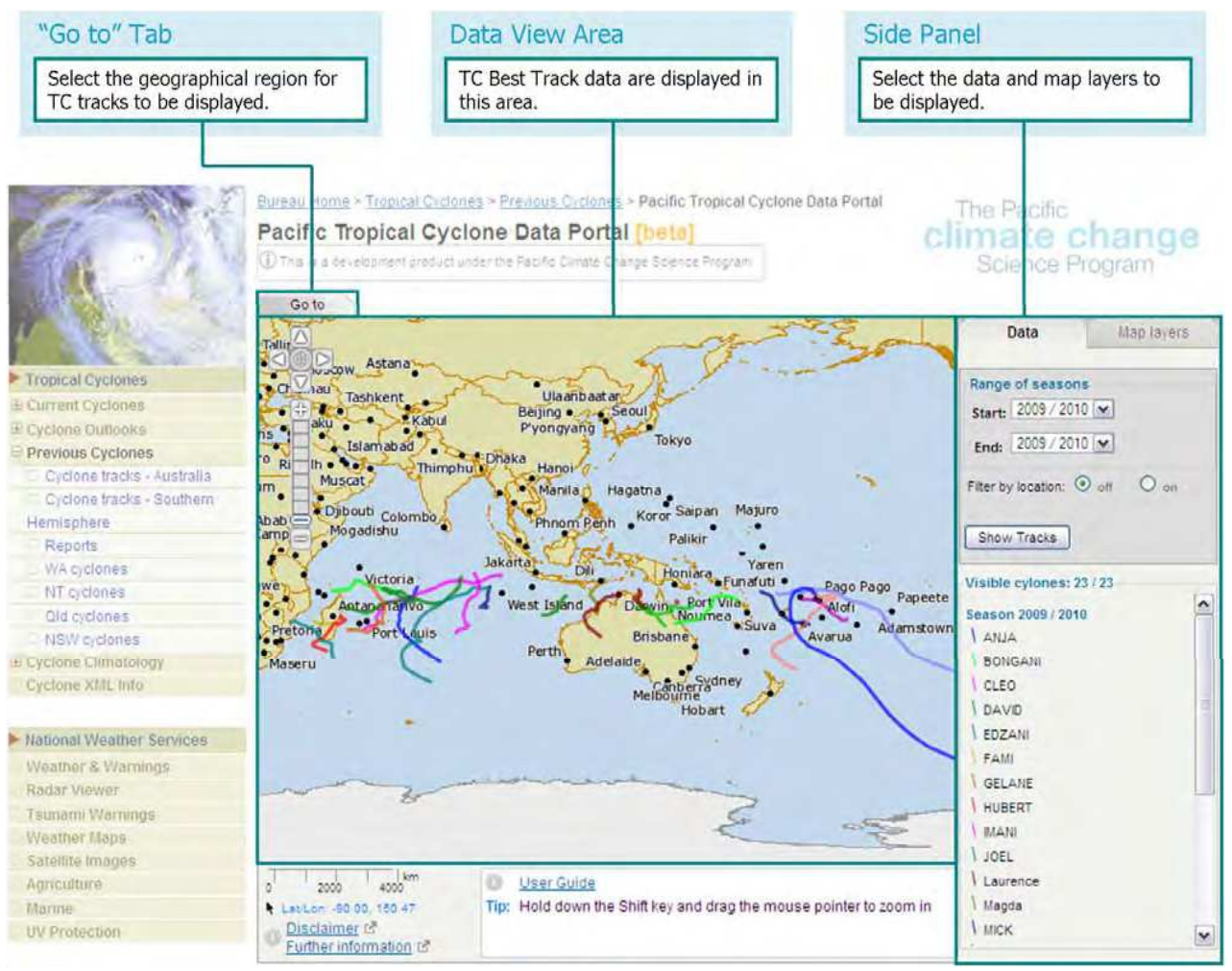

Fig. 26. Front page of the Southern Hemisphere tropical cyclone specialised website.

\section{HETA}

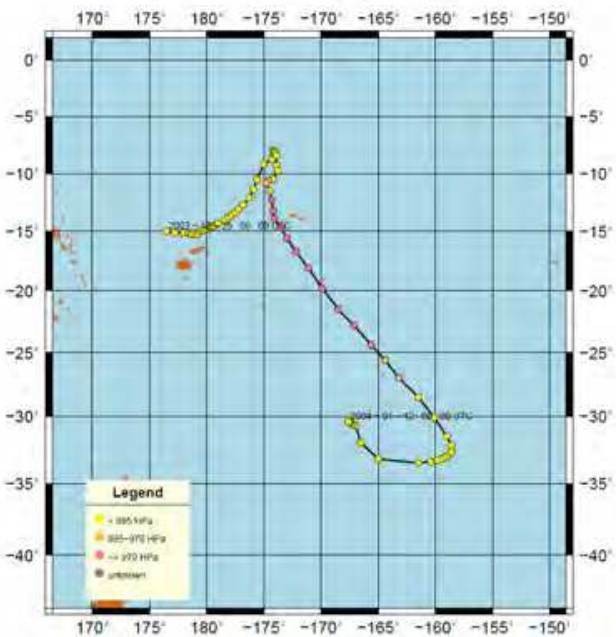

Fig. 27. Best track of tropical cyclone Heta. 


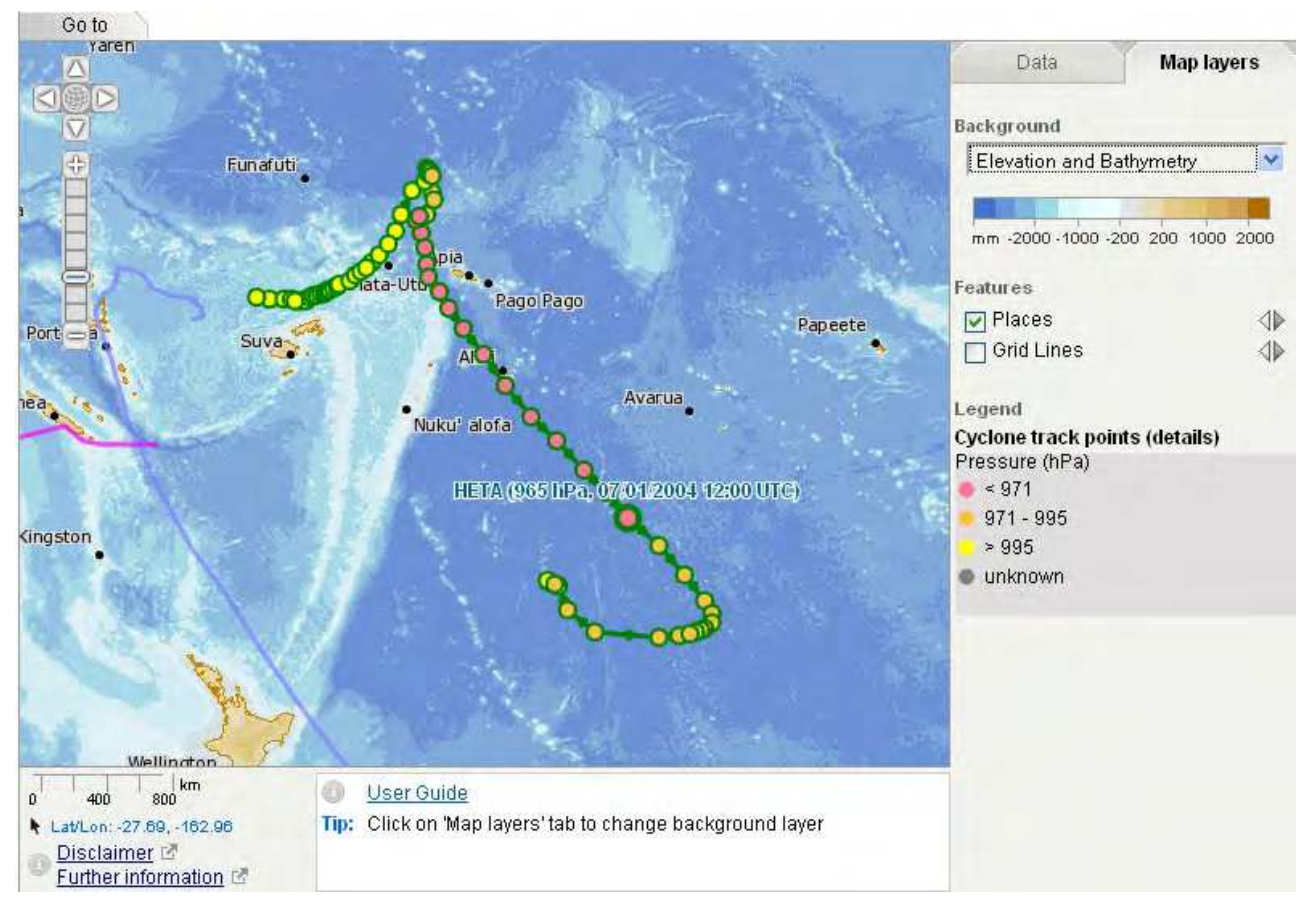

Fig. 28. Detailed presentation of tropical cyclone Heta best track over the selected area where the cyclone reached $915 \mathrm{hPa}$ intensity on January 6, 2004.

\section{Summary}

Tropical cyclones (TCs) in the South Indian Ocean and the South Pacific Ocean are frequent and intense, and they dramatically affect maritime navigation and the lives of communities in coastal areas. To understand TC variability and changes in this region, "Climate change and Southern Hemisphere tropical cyclones" international initiative has been established in 1999. Over more than a decade, significant progress has been made through dedicated international efforts. A new high-quality TC data set has been created and subsequently used to examine variability in TC activity in the Southern Hemisphere (SH). Data from a number of NMHSs were combined in a high-quality tropical cyclone dataset, available through a specialised website "Tropical Cyclones in the Southern Hemisphere". Previously, many of these data have been only available to a small number of individuals, and tended to be fragmented and inconsistent across national borders. Analyses have been undertaken to understand the variability and change in TCs across the $\mathrm{SH}$, with a view to providing a better scientific basis for understanding the current risks posed by TCs, and possible changes as a result of climate change. 
A particularly important finding is that much of the variability of TCs can be understood (and even predicted in advance) using broad-scale indices which describe the El NiñoSouthern Oscillation (ENSO) phenomenon. Climatological analysis of TC occurrences in the South Pacific and the South Indian Oceans clearly demonstrates geographical shifts in the positions of maximum TC occurrences as well as changes in intensity of the maxima. This suggests that a key to understanding future changes in TCs lies in understanding how ENSO will change under the enhanced greenhouse effect. Different indices which describe ENSO (the SOI, the SSTA NINO3.4 index, the MEI and the 5VAR index) have been examined, and a collective list of historical El Niño and La Niña events has been developed. Based on this list, TC data from the TC archive for the SH have been stratified, and significant changes in TC occurrences (in terms of geographical distribution and intensity of maxima) depending on warm and cold phases of ENSO have been identified. The TC climatology for El Niño and La Niña years shows a geographical shift in the positions of maxima of TC occurrences in the SH. In the SIO, TC occurrences in El Niño ( La Niña) years in the area between the east African coast and $75^{\circ} \mathrm{E}$ (between around $75^{\circ} \mathrm{E}$ and $\left.135^{\circ} \mathrm{E}\right)$ are higher than in La Niña (El Niño) years. In the SPO, TC occurrences in El Niño ( $\operatorname{La~Niña)~years~in~the~area~east~of~around~} 170^{\circ} \mathrm{E}$ (between around $140^{\circ} \mathrm{E}$ and $170^{\circ} \mathrm{E}$ ) are higher than in La Niña (El Niño) years.

Tropical cyclogenesis climatology over the South Indian and South Pacific Oceans has been developed and changes in geographical distribution of areas favourable for TC genesis related to changes in the ENSO phases have been investigated. To explain these changes, large-scale environmental variables which influence TC genesis and development such as sea surface temperatures (SSTs), relative humidity in mid-troposphere, vertical wind shear and lower tropospheric vorticity have been examined. In the South Indian Ocean, reduction of TC genesis in the western part of the basin and its increase in the eastern part as well as displacement of the area favourable for TC genesis further away from the equator during La Niña events compared to El Niño events can be explained by changes in geographical distribution of relative humidity and vorticity across the basin as primary contributors; positive anomalies of SSTs observed during La Niña seasons in the eastern part of the basin additionally contribute to enhanced cyclogenesis near the Western Australia. In the South Pacific Ocean, changes in geographical distribution of relative humidity and vorticity appear to be the key large-scale environmental factors responsible for enhanced TC genesis in the eastern (western) part of the basin as well as for the northeast (southwest) shift of points of cyclogenesis during El Niño (La Niña) events, with vertical wind shear and SSTs as additional contributing large-scale environmental variables.

The statistical significance of trends in TCs in the South Indian Ocean and the South Pacific Ocean has been examined. Calculation of significance was based on nonparametric Monte Carlo methods, and additionally it was explored whether a constant model, a linear model or a simple break-point model represents a best fit to the data. For the 1981/ 82 to 2006/07 TC seasons, there are no apparent trends in the total numbers of TCs (those tropical systems attaining a minimum central pressure of $995 \mathrm{hPa}$ or lower), nor in numbers of $970 \mathrm{hPa}$ TCs (such TCs being called severe in the Southern Hemisphere). Positive trends in the numbers of $945 \mathrm{hPa}$ and $950 \mathrm{hPa}$ TCs in the South Indian Ocean are significant, but appear to be influenced to some extent by changes in data quality. In the 
Australian region, no significant trends in the total numbers of TCs, or in the proportion of the most intense TCs, have been found.

These findings are important as the data set used constitutes the official best track data archive for the Southern Hemisphere, even though there are uncertainties in TC intensity estimates (mainly prior to the 1990s). Despite all this, the archive represents the current best estimate of recent SH TC climatology. Attempts have been made to prepare consolidated global datasets and there are plans to continue these efforts. However, consolidation of historical data from various regions is currently limited by the inhomogeneity of TC observation and analysis practice, and there is evidently a considerable need for re-analysis of the historical TC data in order to obtain globally homogeneous records. These homogeneity issues place limit our ability at the present time to answer the important question of how TC activity is changing and its possible relationship to global climate change more generally.

\section{Acknowledgements}

Since establishing "Climate Change and Southern Hemisphere Tropical Cyclones" international initiative in 1999, its various aspects were supported by the Australian Greenhouse Office and the Laboratory of the Atmosphere and Cyclones at the University of La Réunion and Météo-France. The Meteorological Services of Australia, Fiji, France and New Zealand provided the TC best track data for the areas of responsibilities of RSMC La Réunion, RSMC Nadi and TCWC Wellington, respectively. Author thanks Philippe Caroff, Jim Davidson and Steve Ready for discussions on quality of regional TC data sets. The research discussed in this chapter was conducted with the partial support of the Pacific Climate Change Science Program (PCCSP) and Pacific-Australia Climate Change Science and Adaptation planning Program (PACCSAP), which are supported by the Australian Agency for International Development (AusAID), in collaboration with the Department of Climate Change and Energy Efficiency (DCCEE), and delivered by the Bureau of Meteorology and the Commonwealth Scientific and Industrial Research Organisation (CSIRO).

\section{References}

Australian Government (1977), Report on cyclone Tracy December 1974. Australian Government Publishing Service, Canberra, $82 \mathrm{pp}$.

Basher, R.E. and Zheng, X. (1995), Tropical cyclones in the Southwest Pacific: Spatial patterns and relationships to Southern Oscillation and sea surface temperature. Journal of Climate, 8, pp. 1249-1260.

Bister, M. and Emanuel, K.A. (1998), Dissipative heating and hurricane intensity, Meteor. Atmos. Phys., 52, 233-240.

Broomhall, M., Grant, I., Majewski, L., Willmott, M., Jones, D. and Kuleshov, Y., (2010), Improving the Australian tropical cyclone database: Extension of GMS satellite image archive. In Indian Ocean Tropical Cyclones and Climate Change, Y. Charabi (Ed.), pp. 199- 206 (NY, Springer) doi: 10.1007/978-90-481-3109-9_24. 
Camargo, S. J., Emanuel, K.A. and Sobel, A.H., (2007), Use of a genesis potential index to diagnose ENSO effects of tropical cyclone genesis. Journal of Climate, 20, pp. 48194834 .

Chan, J.C.L., (2000) Tropical cyclone activity over the western North Pacific associated with El Niño and La Niña events. J. Climate, 13, 2960-2972.

Chan, J. C. L. and K. S. Liu (2009), Interannual variations of tropical cyclone activity in the Southern Hemisphere, Proceeding of the 9th International Conference on Southern Hemisphere Meteorology and Oceanography (9ICSHMO), American Meteorological Society and the Australian Meteorological and Oceanographic Society, Melbourne, Australia (http://www.bom.gov.au/events/9icshmo).

Chan, J.C.L., J.E. Shi and K.S. Liu, (2001) Improvements in the seasonal forecasting of tropical cyclone activity over the western North Pacific. Wea. Forecasting, 16, 491498.

Chan, J. C. L. (2006), Comment on "Changes in Tropical Cyclone Number, Duration, and Intensity in a Warming Environment", Science, 311, 1713.

Chu, P.-S. (2004), ENSO and tropical cyclone activity. Hurricanes and Typhoons : Past, Present and Potential, R.J. Murnane and K.B. Liu ed., Columbia University Press, New-York, 297-332.

DeMaria M., (1996) The effect of vertical shear on tropical cyclone intensity change. J. Atmos. Sci., 53, 2076-2087.

Dowdy, A. and Y. Kuleshov (2011), An analysis of tropical cyclone occurrence in the Southern Hemisphere derived from a new satellite-era dataset, Int. J. of Remote Sensing (in press).

Dvorak, V. F. (1984), Tropical cyclone intensity analysis using satellite data. NOAA Tech. Report NESDIS 11. 47pp.

Emanuel, K. A. (1987), The dependence of hurricane intensity on climate, Nature, 326, 483485.

Emanuel, K. A. (2005), Increasing destructiveness of tropical cyclones over the past 30 years, Nature, 436, 686-688.

Evans, J.L. and Allan, R.J., (1992), El Niño/Southern Oscillation modification to the structure of the monsoon and tropical cyclone activity in the Australian region. Int. J. Climatol., 12, pp. 611-623.

Goh, A. Z.-C. and J. C. L. Chan (2009), Interannual and interdecadal variations of tropical cyclone activity in the South China Sea. Int. J. Climatol. doi: 10.1002/joc.1943.

Gray, W.M. (1968), Global view of the origin of tropical disturbances and storms, Mon Wea. Rev., 96, 669-700.

Gray, W.M., (1979), Hurricanes: Their formation, structure and likely role in the tropical circulation. Meteorology over the Tropical Oceans, D.B. Shaw, Ed., Royal Meteorological Society, 155-218.

Gray, W.M., (1984), Atlantic seasonal hurricane frequency. Part I: El Niño and $30 \mathrm{mb}$ quasi-biennial oscillation influences. Mon. Wea. Rev., 112, 1649-1668.

Gray, W.M., (1988), Environmental influences on tropical cyclones. Aust. Meteor. Mag., 36, 127-139. 
Hall, T.M. and S. Jewson, (2007), Statistical modelling of North Atlantic tropical cyclone tracks. Tellus, 59A, 486-498.

Harper, B. A., S. A. Stroud, M. McCormack, and S. West (2008), A review of historical tropical cyclone intensity in northwestern Australia and implications for climate change trend analysis, Aust. Met. Mag., 57, 121-141.

Hastings, P.A. (1990), Southern Oscillation influences on tropical cyclone activity in the Australian/ South-west Pacific region, Int. J. Climatol., 10, 291-298.

Ho, C.H., Kim, J.H., Jeong, J.H. and Kim, H.S., (2006), Variation of tropical cyclone activity in the South Indian Ocean: El Niño - Southern Oscillation and Madden-Julian Oscillation effects. Journal of Geophysical Research, 111, D22191, doi:10.1029/2006JD007289.

Holland, G. J. (1997), The maximum potential intensity of tropical cyclones, J. Atmos. Sci., $54,2519-2541$.

Holland, G.J., (1981), On the quality of the Australian tropical cyclone data base. Aust. Meteor. Mag., 29, 169-181.

Holland, G.J., (1984), On the climatology and structure of tropical cyclones in the Australian / southwest Pacific region: I. Data and tropical storms. Australian Meteorological Magazine, 32, pp. 1-15.

IPCC (2007), IPCC WG1 AR4 Report: ipcc-wg1.ucar.edu/wg1/wg1-report.html

Jury, M. R., (1993), A preliminary study of climatological associations and characteristics of tropical cyclones in the SW Indian Ocean. Meteor. Atmos. Phys, 51, 101-115.

Kalnay, E., Kanamitsu, M., Kistler, R., Collins, W., Deaven, D., Gandin, L., Iredell, M., Saha, S., White, G., Woollen, J., Zhu, Y., Leetmaa, A., Reynolds, B., Chelliah, M., Ebisuzaki, W., Higgins, W., Janowiak, J., Mo, K.C., Ropelewski, C., Wang, J., Jenne, R. and Joseph, D. (1996), The NCEP/NCAR 40-Year Reanalysis Project, Bull. Amer. Meteor. Soc.: 77, 437-472.

Kerr, I.S., (1976), Tropical storms and hurricanes in the southwest Pacific, November 1939 to April 1969. NZMS Misc. Publication 148, New Zealand Meteorological Service, pp. 114.

Kiladis, G.N., and H. van Loon, (1988), The Southern Oscillation. Part VII: Meteorological anomalies over the Indian and Pacific sectors associated with extremes of the oscillation. Monthly Weather Review, 116, 120-136.

Knaff, J.A., and R. M. Zehr (2007). Reexamination of tropical cyclone wind-pressure relationships, Wea. Forecasting, 22, 71-88.

Knutson, T. R., T. L. Delworth, K. W. Dixon, I. M. Held, J. Lu, V. Ramaswamy, M. D. Schwarzkopf, G. Stenchikov and R. J. Stouffer (2006), Assessment of twentiethcentury regional surface temperature trends using the GFDL CM2 coupled model, J. Clim., 19, 1624-1651.

Kossin, J. P., K. R. Knapp, D. J. Vimont, R. J. Murnane, and B. A. Harper (2007), A globally consistent reanalysis of hurricane variability and trends, Geophys. Res. Lett., 34, L04815, doi:10.1029/2006GL028836.

Kuleshov, Y. (2003), Tropical cyclone climatology for the Southern Hemisphere. Part I. Spatial and temporal profiles of tropical cyclones in the Southern Hemisphere. Commonwealth of Australia, Bureau of Meteorology, 20 pp. 
Kuleshov, Y., and G. de Hoedt, (2003), Tropical cyclone activity in the Southern Hemisphere. Bull. Austral. Met. Ocean. Soc., 16, 135-137.

Kuleshov, Y. Qi, L., Fawcett, R., Jones, D., (2008), On tropical cyclone activity in the southern hemisphere: Trends and the ENSO connection. Geophysical Research Letters, 35, L14S08, doi:10.1029/2007GL032983.

Kuleshov, Y., Ming, F.C., Qi, L., Chouaibou, I., Hoareau, C. and Roux, F., (2009a), Tropical cyclone genesis in the Southern Hemisphere and its relationship with the ENSO. Ann. Geophys., 27, pp. 2523-2538.

Kuleshov, Y. Qi, L., Fawcett, R., Jones, D., (2009b), Improving preparedness to natural hazards: Tropical cyclone prediction for the Southern Hemisphere. In Advances in Geosciences, 12 Ocean Science, J. Gan (Ed.), pp. 127-143 (Singapore: World Scientific Publishing).

Kuleshov, Y., Fawcett, R., Qi, L., Trewin, B., Jones, D., McBride, J. and Ramsay, H., (2010a), Trends in tropical cyclones in the South Indian Ocean and the South Pacific Ocean. Journal of Geophysical Research, 115, doi:10.1029/2009JD012372.

Kuleshov, Y. Qi, L., Jones, D., Fawcett, R., Chane-Ming, F., McBride, J. and Ramsay, H. (2010b), On developing a tropical cyclone archive and climatology for the South Indian and South Pacific Oceans, In Indian Ocean Tropical Cyclones and Climate Change, Y. Charabi (Ed.), pp. 189-197 (NY: Springer), doi: 10.1007/978-90-4813109-9_23.

Landsea, C.W., (2000a), Climate Variability of Tropical Cyclones: Past, Present and Future Storms, 2000 Ed. R.A. Pielke, Sr. and R.A. Pielke, Jr, Routledge, New York, 220241.

Landsea, C.W., (2000b), El Niño/Southern Oscillation and the Seasonal Predictability of Tropical Cyclones. In El Niño and the Southern Oscillation: Multiscale Variability and Global and Regional Impacts, H.F. Diaz and V. Markgraf, Ed., Cambridge University Press, 149-181.

Landsea, C. W., B. A. Harper, K. Hoarau, and J. A. Knaff (2006), Can we detect trends in extreme tropical cyclones, Science, 313, 452-454.

Larkin, N.K., and D.E. Harrison, (2001), Tropical Pacific ENSO cold events, 1946-95, SLP, and surface wind composite anomalies, J. Climate, 14, 3904-3930.

Larkin, N.K., and D.E. Harrison, (2002), ENSO warm (El Niño) and cold (La Niña) event life cycles: ocean surface anomaly patters, their symmetries, asymmetries, and implications, J. Climate, 15, 1118-1140.

Maloney E. D. and Hartmann D. L. (2000), Modulation of Eastern North Pacific Hurricanes by the Madden-Julian Oscillation. J. Climate, 13, 1451-1460.

Merrill, R. T. (1988), Environmental influences on hurricane intensification. J. Atmos. Sci., $45,1678-1687$.

Nicholls, N., (1984), The Southern Oscillation, sea-surface temperature, and inter-annual cyclone activity in the Australian region. J. Climatol., 4, 661-670.

Nicholls, N., (1985) Predictability of interannual variations of Australian seasonal tropical cyclone activity. Mon. Wea. Rev., 113, 1144-1149.

Nicholls (1992), Recent performance of a method for forecasting Australian seasonal tropical cyclone activity. Aust. Meteor. Mag., 40, 105-110. 
Nicholls, N., Landsea, C.W. and Gill, J. (1998), Recent trends in Australian region tropical cyclone activity, Meteor. Atmos. Phys., 65, 197-205.

Rasmusson, E.M. and T.H. Carpenter, (1982), Variations in tropical sea surface temperature and surface wind fields associated with the Southern Oscillation/El Niño, Monthly Weather Review, 110, 354-384.

Reid, P.A. (2003), An operational definition of El Niño. Proc. 7th Int. Conf. on Southern Hemisphere Meteorology and Oceanography, Wellington NZ, 24-28 March 2003, 128130.

Revell, C.G., (1981), Tropical cyclones in the Southwest Pacific, November 1969 to April 1979. NZMS Misc. Publication 170, New Zealand Meteorological Service, pp. 53.

Revell, C.G. and Goulter, S.W., (1986), South Pacific tropical cyclones and the Southern Oscillation, Mon. Wea. Rev., 114, pp. 1138-1145.

Saunders, M.A., R.E. Chandler, C.J. Merchant, and F.P. Roberts, (2000), Atlantic hurricanes and NW Pacific typhoons: ENSO spatial impacts on occurrence and landfall. Geophys. Res. Lett., 27, 1147-1150.

Shapiro, L.J., (1987), Month-to-month variability of the Atlantic tropical circulation and its relationship to tropical storm formation. Mon. Wea. Rev., 115, 2598-2614.

Sinclair M. R., (2002), Extratropical transition of Southwest Pacific Tropical Cyclones. Part 1: Climatology and Mean Structure Changes. Monthly Weather Review, 130, pp. 590-609.

Trenberth, K.E., (1997), The definition of El Niño. Bull. Amer. Meteor. Soc., 78, 2771-2777.

Trenberth, K.E., (2007), Warmer oceans, stronger hurricanes. Scientific American, July 2007, 45-51.

Trewin, B. (2008), An enhanced tropical cyclone data set for the Australian region, $20^{\text {th }}$ Conference on Climate Variability and Change, Abstract JP3.1.

Troup, A.J., (1965), The Southern Oscillation. Q. J. Royal Met. Soc., 91, 490-506.

Velden, C., B. Harper, F. Wells, J. L. Beven II, R. Zehr, T. Olander, M. Mayfield, C. (Chip) Guard, M. Lander, R. Edson, L. Avila, A. Burton, M. Turk, A. Kikuchi, A. Christian, P. Caroff and P. McCrone (2006), The Dvorak tropical cyclone intensity estimation technique: A satellite-based method that has endured for over 30 years, Bull. Am. Meteorol. Soc., 87, 1195-1210.

Webster, P. J., G. J. Holland, J. A. Curry and H.-R. Chang (2005), Changes in tropical cyclone number, duration, and intensity in a warming environment, Science, 309, 1844-1846.

WMO (1993), WMO/TD No. 560. Global Guide to Tropical Cyclone Forecasting. G.J. Holland, Ed. Report No. TCP-31

WMO (2002a), WMO/TD No. 292. Tropical cyclone operational plan for the South Pacific and South-east Indian Ocean. Report No. TCP-24.

WMO (2002b), WMO/TD No. 577: Tropical cyclone operational plan for the South-west Indian Ocean. Report No. TCP-12.

Wolter, K., (1987), The Southern Oscillation in surface circulation and climate over the tropical Atlantic, Eastern Pacific, and Indian Oceans as captured by cluster analysis. J. Climate Appl. Meteor., 26, 540-558. 
Zehr, R.M., (2003), Environmental vertical wind shear with Hurricane Bertha (1996), Wea. Forecasting, 18, 345-356. 


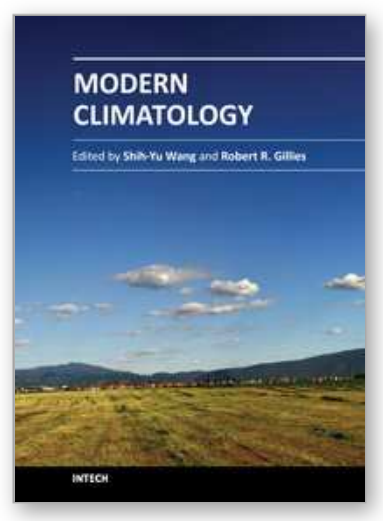

\author{
Modern Climatology \\ Edited by Dr Shih-Yu Wang
}

ISBN 978-953-51-0095-9

Hard cover, 398 pages

Publisher InTech

Published online 09, March, 2012

Published in print edition March, 2012

Climatology, the study of climate, is no longer regarded as a single discipline that treats climate as something that fluctuates only within the unchanging boundaries described by historical statistics. The field has recognized that climate is something that changes continually under the influence of physical and biological forces and so, cannot be understood in isolation but rather, is one that includes diverse scientific disciplines that play their role in understanding a highly complex coupled "whole system" that is the earth's climate. The modern era of climatology is echoed in this book. On the one hand it offers a broad synoptic perspective but also considers the regional standpoint, as it is this that affects what people need from climatology. Aspects on the topic of climate change - what is often considered a contradiction in terms - is also addressed. It is all too evident these days that what recent work in climatology has revealed carries profound implications for economic and social policy; it is with these in mind that the final chapters consider acumens as to the application of what has been learned to date.

\title{
How to reference
}

In order to correctly reference this scholarly work, feel free to copy and paste the following:

Yuriy Kuleshov (2012). Southern Hemisphere Tropical Cyclone Climatology, Modern Climatology, Dr Shih-Yu Wang (Ed.), ISBN: 978-953-51-0095-9, InTech, Available from: http://www.intechopen.com/books/modernclimatology/southern-hemisphere-tropical-cyclone-climatology

\section{INTECH}

open science | open minds

\section{InTech Europe}

University Campus STeP Ri

Slavka Krautzeka 83/A

51000 Rijeka, Croatia

Phone: +385 (51) 770447

Fax: +385 (51) 686166

www.intechopen.com

\section{InTech China}

Unit 405, Office Block, Hotel Equatorial Shanghai

No.65, Yan An Road (West), Shanghai, 200040, China

中国上海市延安西路65号上海国际贵都大饭店办公楼 405 单元

Phone: +86-21-62489820

Fax: $+86-21-62489821$ 
(C) 2012 The Author(s). Licensee IntechOpen. This is an open access article distributed under the terms of the Creative Commons Attribution 3.0 License, which permits unrestricted use, distribution, and reproduction in any medium, provided the original work is properly cited. 